\title{
THE EFFECTS OF DIETARY RESTRAINT AND PORTION-CONTROL PACKAGING ON SNACK CONSUMPTION BEHAVIOUR
}

\author{
by \\ Katey Ellen Park \\ Bachelor of Arts (Honours), University of Guelph, 2013
}

\author{
A thesis \\ presented to Ryerson University \\ in partial fulfillment of the \\ requirements for the degree of \\ Master of Arts \\ in the program of \\ Psychology \\ Toronto, Ontario, Canada, 2017 \\ (C) Katey Ellen Park, 2017
}




\section{AUTHOR'S DECLARATION FOR ELECTRONIC SUBMISSION OF A THESIS}

I hereby declare that I am the sole author of this thesis. This is a true copy of the thesis, including any required final revisions, as accepted by my examiners.

I authorize Ryerson University to lend this thesis to other institutions or individuals for the purpose of scholarly research.

I further authorize Ryerson University to reproduce this thesis by photocopying or by other means, in total or in part, at the request of other institutions or individuals for the purpose of scholarly research.

I understand that my thesis may be made electronically available to the public. 
The Effects of Dietary Restraint and Portion-Control Packaging on

Snack Consumption Behaviour

Master of Arts, 2017

Katey Ellen Park

Psychology

Ryerson University

\begin{abstract}
The present study investigated the effects of package size on consumption behaviour when either body image or dietary concerns are activated, in restrained and unrestrained eaters. Portion-control packaging has recently emerged under the assumption that carefully-controlled portion sizes help limit consumption of palatable snacks. While there is reasonably good support for this in most populations, recent findings suggest that portion-control packaging may paradoxically increase consumption for restrained eaters (Coelho Do Vale, Pieters, \& Zeelenberg, 2008; Scott et al., 2008). Consistent with prior research, we hypothesized that restrained eaters activated for dieting or body image concerns are more likely to deem larger packaged-sized treats as "unacceptable" and decrease intake. Similarly, activated restrained eaters are more likely to deem smaller packaged-sized treats as "acceptable" and thus paradoxically increase intake. However, the present study did not find support for hypotheses. Theoretical reasons as to why results were not what researchers anticipated are proposed.
\end{abstract}




\section{Acknowledgements}

I gratefully acknowledge my supervisor, Dr. Michelle Dionne, for your encouragement, immense knowledge, and innovative ideas throughout this project. Your wonderful mentorship has made pursing graduate studies a pleasurable experience.

Thank you also to my supervisory committee, Dr. Stephen Want and Dr. Kristin Vickers, for providing constructive feedback and valuable guidance throughout this dissertation project.

Thank you to Bronwyn Laforet for your countless hours aiding in data collection. Your enthusiasm and good company has made this project infinitely more enjoyable.

Finally, thank you to my friends and family who encouraged me every step of the way. To my parents, Mary and Glen, for your endless support. To my brother, Craig, for inspiring me to pursue graduate studies and demonstrating that it is possible. To my partner, Keegan, for your constant encouragement and laughter when it was needed most. And to my son, Emerson, for being my biggest motivator and almost always sleeping through the night. Thank you. 


\section{Table of Contents}

Author Declaration .......................................................................................... ii

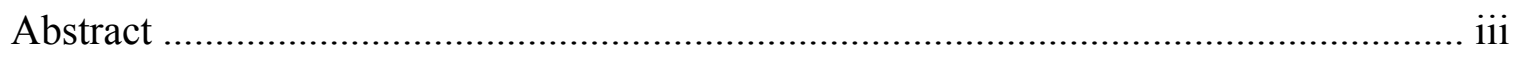

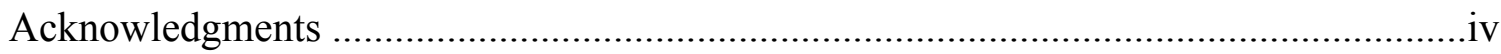

List of Tables ................................................................................................... vii

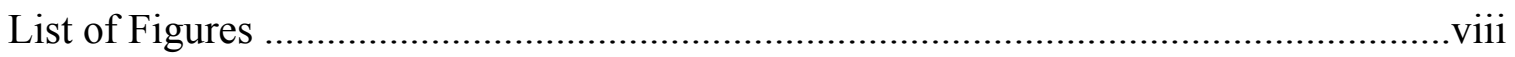

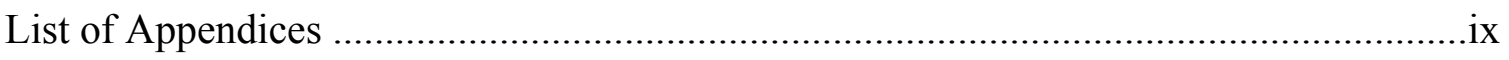

\section{Introduction}

1.1 Rationale \& Purpose ....................................................................................

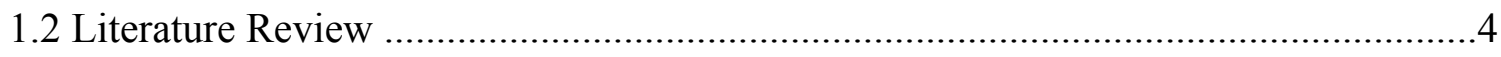

1.2.1 Portion Size and Consumption Behaviour ............................................4

a. Portion Control Packaging...................................................................4

b. Portion Size Effect........................................................................

1.2.2. Restrained Eaters ..........................................................................

a. Diet Primes and Impact on Consumption Behaviour ............................10

b. Moderating Role of Dietary Restraint on Diet Primes and Portion Control

Packaging...................................................... 11

i. Restrained Eaters Consume More from Smaller Foods in Smaller

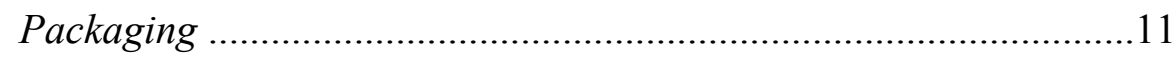

ii. Activating Body Consciousness Reduces Consumption of Larger

Packaging ............................................................................ 12

iii. Both Diet "Manipulated" and Diet "Measured" Individuals

Consume More from Smaller Packaging .......................................13 
iv. Restrained Eaters Consume Less from Large Packaging After

Exposure to a Diet Prime ................................................................15

1.2.3. Theoretical Explanations ..........................................................................

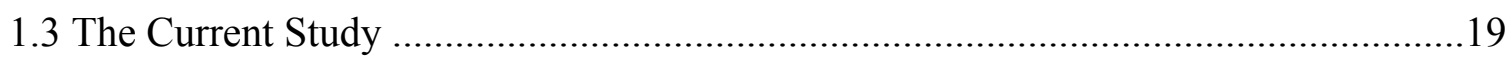

\section{Method}

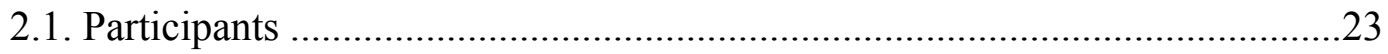

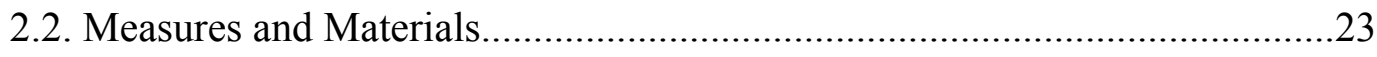

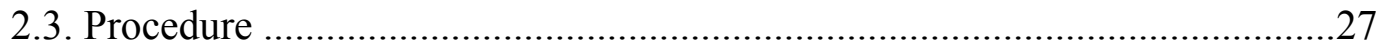

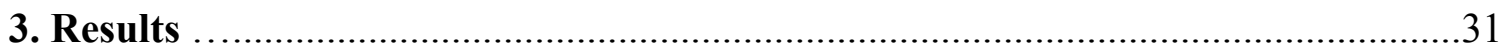

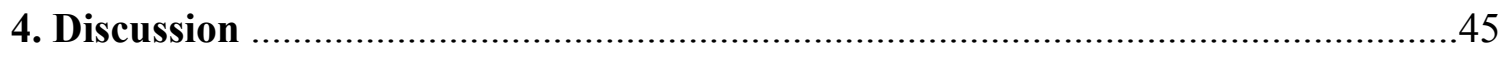

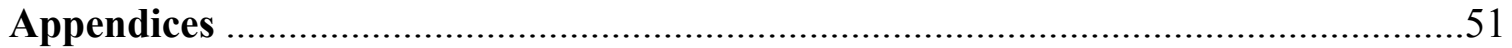

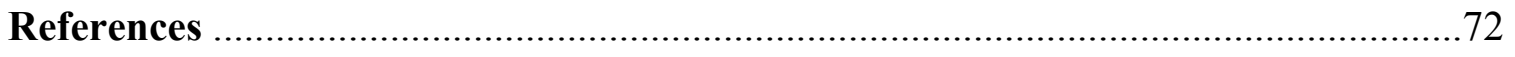




\section{List of Tables}

Table 1: Demographic Characteristics....................................... 32

Table 2: Bivariate Correlational Analyses between Continuous Variables................35

Table 3: Point Biserial Correlational Analyses between Nominal and Continuous

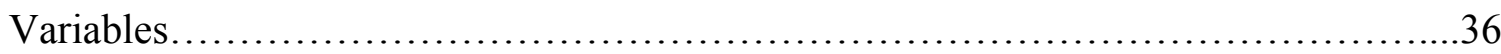

Table 4: Dietary Restraint, Package Size, and Prime Condition on Snack Consumption

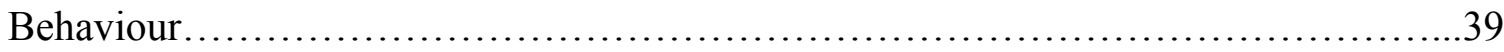




\section{List of Figures}

Figure 1: Consumption Behaviour in Body Image Prime Condition..................40

Figure 2: Consumption Behaviour in Diet Prime Condition..........................41

Figure 3: Consumption Behaviour in Control Condition...........................42

Figure 4: Consumption Behaviour in Small Packaging Across Prime Conditions........43

Figure 5: Consumption Behaviour in Large Packaging Across Prime Conditions.........44 


\section{List of Appendices}

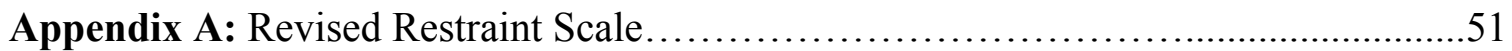

Appendix B: Demographic Questionnaire........................................................5

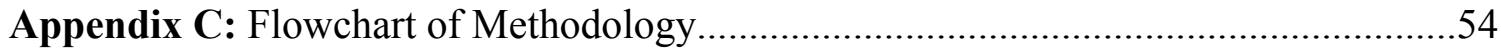

Appendix D: Images of Package Sizes . .........................................................55

Appendix E: Activating Body Consciousness Scale........................................56

Appendix F: Activating Diet Consciousness Scale...........................................58

Appendix G: Activating Diet Consciousness Behavioural Component......................60

Appendix H: Control Questionnaire: Political Affiliation Scale................................61

Appendix I: Control (Body Neutral) Behavioural Component..................................63

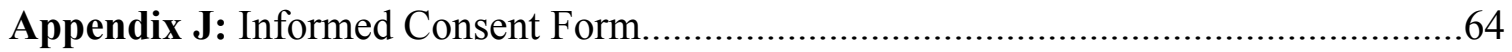

Appendix K: Filler Questionnaires during Eating Task.........................................67

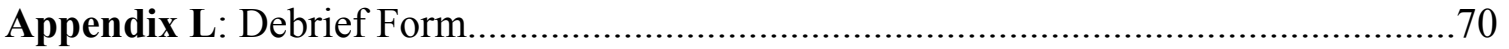




\subsection{Rationale and Purpose}

Consumers have attempted to manage snack consumption behaviour by selecting calorically indulgent, but smaller-sized, packages in an effort to reduce excessive energy intake and ultimately curtail weight gain (Friedman, 2009; Wertenbroch, 1998). While offering smaller portion sizes typically decreases the amount of food consumed (Diliberti, Bordi, Conklin, Roe, \& Rolls, 2004; Levitsky, \& Youn, 2004; Stroebele, Ogden, \& Hill, 2009; Wansink, 2004; Wansink, Payne, \& Shimizu, 2011), presenting multiple smaller packages rather than one large package can have paradoxical effects for some types of consumers (Holden \& Zlatevska, 2015). Specifically, restrained eaters or diet-conscious consumers may actually eat more food from portion-control packaging compared to larger packaging (Coelho Do Vale, Pieters, \& Zeelenberg, 2008; Scott, Nowlis, Mandel, \& Morales, 2008). Portion control packaging can adopt various names within the portion size literature, including partitioned packaging, single-serving snacks, pre-portioned foods, or X-calorie packs (e.g., 100-calorie packages). Although slightly varying in name, these constructs are common in that they are smaller, carefully controlled package sizes, and generally are intended to exert consumer self-control and inhibit snacking behaviour (“Obesity: Can Packaging Help?,” 2005).

The "partitioning paradox" refers to the phenomenon that restrained eaters may contradictorily consume more food from smaller packaging, resulting in consumption behaviour opposite of the product's intended goal (Holden \& Zlatevska, 2015). This effect can be quite concerning for the buying and consumption behaviour of restrained eaters. If food-marketing companies are developing products specifically designed for diet-conscious individuals (e.g., 100-calorie packages), and these products paradoxically 
increase consumption behaviour and promote the opposite of the intended effects (Holden \& Zlatevska, 2015), then understanding the partitioning paradox is of great importance for both theoretical and applied purposes. Researchers are only now investigating mechanisms that promote the partitioning paradox and attempting to explain why dietary restraint may cause such an effect.

Dietary restraint is traditionally defined as the cognitive intent to restrict consumption behaviour in order to lose or maintain weight (Herman \& Mack, 1975; Herman \& Polivy, 1975). Individuals rating high on dietary restraint, often referred to as restrained eaters, are commonly vulnerable to overeating and binge eating episodes (Schmidt \& Martin, 2015; Polivy, Coleman, \& Herman, 2005), and this is particularly true for overweight restrained eaters when presented with an attractive food (Ouwehand \& Papies, 2010). Restrained eaters are also more likely to purchase "diet foods," such as foods with reduced kilocalories (Rideout, McLean, \& Barr, 2004; Tuschl, Laessle, Platte, \& Pirke, 1990), including 100-calorie packages (Holden \& Zlatevska, 2015). Therefore from an applied perspective, the partitioning paradox could mean that restrained eaters are at a greater risk for weight gain if they are more likely to purchase portion control packaging, and are also more likely to consume more food from snacks packaged in this format.

Some limited research that has been done in this area shows that priming participants with dieting or body image cues can inhibit snacking behaviour, presumably because it reminds restrained eaters of their dieting goals (Anschutz, Van Strien, Engels, \& Rutger, 2008; Buckland, Finlayson, Edge, \& Hetherington, 2014; Papies, \& Hamstra, 2010; Veling, \& Papies, 2013). Furthermore, priming restrained participants with dieting 
or body image cues can also foster the partitioning paradox, and increase consumption of smaller packaging compared to larger packaging (Coelho do Vale, Pieters, \& Zeelenberg, 2008; Versluis, \& Papies, 2016). For example, Coelho do Vale and colleagues (2008) found that priming participants for "body consciousness" resulted in participants increasing consumption of potato chips from smaller packaging compared to larger packaging. Similarly, Versluis and Papies (2016) discovered that exposure to a dieting prime reduced restrained eaters' consumption of bigger packages compared to the control no-prime condition. The present study is unique in that it aims to compare the effects of both a body satisfaction and a diet prime, separately, on consumption behaviour.

Although influential studies, both Coelho do Vale et al. (2008) and Versluis and Papies' (2016) research had methodological limitations in regards to their primes. Specifically, Coelho do Vale et al. (2008) primed participants for "body consciousness." In order to activate this construct, participants completed a variety of scales on body image, body satisfaction, and dieting behaviour. Consequently, participants were primed for both body image and dieting cues in the same experimental condition. Likewise, Versluis and Papies (2016) exposed participants to diet commercials in order to activate a diet-prime. However, the diet commercials also included media images of thin women, which commonly prompts body dissatisfaction (Becker, 2004; Ferguson, 2013; Hausenblas, et al., 2013). Therefore, previous research purportedly evaluating the effects of body image or dieting primes on the partitioning paradox has confounded primes. The present study aims to parse apart these constructs and determine which prime, dieting or body image, has the greatest effect on the partitioning paradox. 
Therefore, the present study aims to better understand why and under what conditions the partitioning paradox occurs, and to what extent restraint moderates this effect. Specifically, the current study evaluates the effects of providing either a body image or diet-prime prior to presenting a snack in either multiple small, or one large, package. Importantly, we aim to determine if being a restrained eater moderates the relationship between the type of prime exposure (e.g., body image or dieting), and the amount of snack consumed.

\subsection{Literature Review}

\subsubsection{Portion Size and Consumption Behaviour}

Portion Size refers to the amount of food chosen to eat at one time, whether selected by the individual or pre-selected by a restaurant or other food manufacturer ("Portion Size," 2016). There is ample evidence demonstrating that portion sizes have increased dramatically over the past thirty years (Benton, 2015; Nielsen, \& Popkin, 2003; Piernas, \& Popkin, 2011; Steenhuis, Leeuwis, \& Vermeer, 2010). The increased marketing of larger portion sizes has paralleled climbing obesity rates (Young \& Nestle, 2012), thus larger portion sizes have been considered as a crucial contributing factor to weight gain and obesity (Berg et al., 2009; Young, \& Nestle, 2002). However, the relationship between increased portion sizes and weight gain is complex, as there is a multitude of other factors that influence portion size selection and consumption behaviour (Benton, 2015).

\section{A. Portion Control Packaging}

The food industry has recently targeted audiences seeking to control their consumption by offering portion control packaging. Cookies, chips, and other popular 
snacks are now advertised and sold in "100-calorie" format (Scott, Nowlis, Mandel, \& Morales, 2008). From a business standpoint, the financial success of portion control packaging is clear. The first year these products were introduced, Kraft profited $\$ 100$ million, and they continued to launch new treats into smaller packages given their success (Thompson, 2006). In 2004 when pre-portioned 100-calorie packages were first introduced, only five products were available. The number of products available on shelves jumped to 44 just one year later (Thompson, 2006).

These developments have arisen under the assumption that carefully-controlled, (smaller) portion sizes help limit consumption of tempting treats and can reduce consumers' overall energy intake. Consumers themselves perceive portion control packaging to be a useful tool for maintaining self-control (Spence et al., 2013) and are willing to pay a premium for products that help constrain consumption behaviour (Thompson, 2006). Although the food industry has developed these products as a means of helping individuals inhibit consumption behaviour, as previously discussed, recent findings suggest that portion-control packaging may not necessarily reduce consumption or be a useful means in exerting self-control for restrained or diet-conscious consumers (Coelho Do Vale, Pieters, \& Zeelenberg, 2008; Scott et al., 2008; Versluis \& Papies, 2016).

\section{B. Portion Size Effect}

The portion-size effect refers to the tendency to eat more food when served larger portions (Herman, Polivy, Pliner, \& Vartanian, 2015). Portion size effects have been found in controlled laboratory settings (Rolls, Roe, \& Meengs, 2006; 2007); naturalistic settings, such as restaurants or at work (Diliberti et al., 2004; French et al., 2014; Jeffery 
et al., 2007); with beverages as well as food (Flood, Roe, \& Rolls, 2006); with both palatable (Birch, Savage, \& Fisher, 2015; Fisher \& Kral, 2008), and unpalatable foods (Wansink \& Kim, 2005); in larger unit sizes of foods (iron-Roig, Solis-Trapala, Dodd, \& Jebb, 2013; Kleef, Vet, \& Bruggers, 2015); and low-energy dense foods, such as fruits and vegetables (Kral, Kabay, Roe, \& Rolls, 2010; Mathias et al., 2012).

The portion size effect has also been discovered with packaged snacks, although the results are not straightforward. For example, Rolls et al. (2004) presented participants with five commercially available package sizes of potato chips and found that the bigger the package presented, the greater the combined caloric intake from the snack and a subsequent meal. Similarly, Wansink, Payne, and Shimizu (2011) found that undergraduate students ate $25 \%$ fewer crackers when given four 100 -calorie packages, compared to one 400-calorie package while watching television. Stroebele, Ogden, and Hill (2009) also found that providing snacks with 100-calorie packages reduced consumption behaviour over a two-week period. Finally, Haire and Raynor (2014) found that participants with a BMI classified as overweight or obese consumed fewer pretzels packaged in a smaller "single serving" format, compared to a larger standard package size.

However, dietary restraint and body image or dieting primes may play a crucial role in reducing the portion size effect for packaged snacks. Scott et al., (2008) found that chronic dieters (also referred to as restrained eaters) consumed more food from smaller packages compared to unrestrained eaters who consumed more food from larger packages. Similarly, Coelho do Vale et al. (2008) found that when palatable treats came in large or small packaging and participants were primed for concerns about their body, 
subjects consumed the least from larger packaging compared to both smaller packaging, and larger packaging when a body image prime was not activated. In this study, selfregulatory concerns were experimentally activated, but pre-existing dietary restraint status of the individual (e.g., restrained or unrestrained eaters) was not assessed. Finally, Versluis and Papies (2016) found that a diet prime reduced the portion size effect for restrained eaters, and thus chronic dieters ate less from larger packages compared to the control, no-prime condition. These findings suggest that perhaps smaller packaging increases consumption for certain types of consumers (e.g., restrained eaters), or under certain conditions (e.g., diet exposure). A more detailed discussion of dietary restraint and how this may serve as a mechanism for this effect will be presented later in this review / in the next section.

Finally, there is support that the so called 'portion size effect' seems to be about portions of food rather than package size per se. For example, Raynor and Wing (2007) found no effect of package size on consumption behaviour. Researchers randomly assigned participants to one of four groups crossing package size (large or small) and actual amount of food (large or small). Although participants ate $81 \%$ more food when a larger amount of food was provided, there was no effect of package size on consumption behaviour. This research suggests that extra exertion of opening multiple smaller packages may not impact eating behaviour. However, this sample only included unrestrained eaters in the experiment and future research should explore the differences in restrained and unrestrained eaters. Furthermore, Haire and Raynor (2014) found that participants with higher BMIs (overweight/obese) ate more food from larger packaging when equivalent portion sizes were provided, but found no effects of dietary restraint on 
package size and consumption behaviour. This is interesting given that BMI and dietary restraint tend to be positively correlated (Goldfield et al., 2010). The inconsistencies of results surrounding package size and consumption behaviour for restrained and unrestrained eaters warrant further investigation.

\subsubsection{Restrained Eaters}

Restrained eaters are individuals who are consciously and continuously aware of their eating behaviour in order to adhere to a particular weight for either appearance or health-related concerns (Herman \& Polivy, 1980; Lowe \& Thomas, 2009). Restrained eaters typically rely on cognitive strategies as a means of regulating eating behaviour (e.g., imposing strict rules about appropriate food consumption) rather than attending to their physical cues such as hunger (Herman \& Polivy, 1992; Herman \& Polivy, 2004; Polivy, Herman, Olmsted, \& Jazwinski, 1984). As follows, restrained eaters, compared to unrestrained eaters, chronically suppress their internal physiological hunger cues and place less emphasis on the biological need for food (Dykes, Brunner, Martikainen, \& Wardle, 2004; Madanat, Hawks, \& Christley, 2008).

An integral element of the restrained eater is his/her highly emotional response to food (Canetti, Bachar, \& Berry, 2002). Restrained eaters are more likely to eat when they are faced with a high-stress situation (compared to a low-stress situation), and are prone to overeating when experiencing feelings of anxiety (Kuijer, Boyce, \& Marshall, 2015; Tanofsky-Kraff, Wilfley, \& Spurrell, 2000; Wardle, Steptoe, Oliver, \& Lipsey, 2000). Similarly, several studies have found that emotional distress suppresses consumption behaviour for unrestrained eaters, but increases consumption in restrained eaters 
(Baucom, \& Aiken, 1981; Heatherton, Polivy, Herman, \& Baumeister, 1993; Lee, Greening, \& Stoppelbein, 2007; McNelis, 2006).

Restrained eaters place a high importance on self-control making them prone to a state of resource depletion and more likely to fall short of their high self-control expectations (Baumeister \& Heatherton, 1996; Polivy \& Herman, 1999). Once restrained eaters experience a break down on their consumption goal, they may trigger disinhibited eating and a "what the hell effect" (Cochran \& Tesser, 1996; Polivy \& Herman, 2010), and continue their food consumption. The What the Hell Effect refers to the notion that once a restrained eater has exceeded their self-imposed "diet boundary" (e.g., eating and/or caloric boundary in which a restrained eater tries to stay within), and thus dieting goals have been sabotaged, restrained eaters tend to disinhibit consumption behaviour and eat until they are full (e.g., "Diet is ruined, may as well keep eating"; Herman, \& Polivy, 1983). After the consumption of a forbidden food, restrained eaters often experience negative affect and feelings of guilt (de Witt Huberts, Evers, \& de Ridder, 2013).

Dietary restraint has also been associated as a risk factor for binge eating (Andrés \& Saldaña, 2014; Racine, Burt, Iacono, McGue, \& Klump, 2011; Stice, 2001), and there have been various explanations for this relationship. For example, dietary restraint may lead to binge eating through the physiological deprivation that occurs alongside chronic dieting (e.g., binge eating as the body's defense to decreases in caloric intake; Nisbett, 1972; Stice, Davis, Miller, \& Marti, 2008). Alternatively, episodes of binge eating may occur when the restrained eater is faced with stress and their usually high levels of 
cognitive controls are temporarily compromised (Policy \& Herman, 1985; Wolff, Crosby, Roberts, \& Wittrock, 2000).

\section{A. Diet Primes and Impact on Consumption Behaviour}

Previous research has demonstrated that exposure to a diet prime and/or exposure to thin images may reduce consumption behaviour for restrained eaters. For example, Anschutz, Van Strien, Engels, and Rutger (2008) found that when highly restrained students were exposed to commercials containing thin models and diet-related products, they consumed less food from two bowls (containing potato chips and M\&M's) compared to unrestrained eaters. These findings suggest that exposure to thin images or diet products remind restrained eaters of their long-term goals, and thus inhibit snacking behaviour. Similarly, Buckland, Finlayson, Edge, and Hetherington (2014) exposed participants to either diet-congruent or neutral images during a lexical decision task (measuring how quickly individuals are able to classify stimuli) and measured intake of tempting snacks from four food options (including bowls of high or low fat and sweet or savoury food). Highly restrained eaters reduced consumption behaviour after exposure to diet-congruent images (e.g., low calorie foods, such as fruits and diet products, paired with diet-congruent words, such as diet, slim, thin and weight), compared to control images, suggesting that diet-congruent cues may be effective at limiting consumption of those most vulnerable to food temptations. Finally, Veling and Papies (2013) found that subtle diet reminders on a restaurant menu (e.g., "Are you also watching your weight?" written beside a salad description) reduced intake for both chronic and current dieters (similar to restrained eaters), suggesting that dieting environmental cues may be effective for reducing consumption. 
Although the above represent evidence that dieting primes can bolster the selfcontrol that restrained eaters value to maintain, under slightly different conditions, we see a different effect. Recent findings have suggested that exposure to diet primes may increase consumption behaviour of smaller packaging for restrained eaters.

\section{B. Moderating Role of Dietary Restraint on Diet Primes and Portion Control}

\section{Packaging}

\section{i. Restrained Eaters Consume More from Smaller Foods in Smaller Packaging}

To my knowledge, there have been three studies (as well as one replication) to date that have suggested that portion control packaging may paradoxically increase consumption under certain conditions.

A study conducted by Scott et al. (2008) assessed the moderating role of dietary restraint on the consumption behaviour of small food in small packaging, and large food in larger packaging. Researchers presented participants with either mini-M\&M's in four small plastic bags, or regular M\&M's in one large plastic bag (both conditions were isocaloric in value). In a second experiment, researchers offered participants either eight mini-cookies in small bags (e.g., two cookies per bag), or four large cookies in one bag. Similar to the previous experiment, both of these conditions were of isocaloric value. In order to measure dietary restraint, participants completed the 10-Item Dietary Restraint Scale (Herman \& Polivy, 1980), which is a well-known measure of dietary restraint (one sample item is, "How often are you dieting?). Somewhat unusually, this scale was completed during the eating task, and it is worth considering that completion of this scale during the experimental session may have inadvertently primed participants to think 
about dieting behaviour. In other words, the measurement of chronic dieting could have also primed self-control around food that might compromise dieting goals.

Both experiments found that restrained eaters consumed more food from smaller packages than from larger packages, whereas unrestrained eaters consumed more food from larger packages than from the smaller packages. Researchers also found that restrained eaters compared to unrestrained eaters were less likely to stop eating from the smaller packages once they began eating, suggesting that were experiencing a lapse in self-control, but particularly with that small-sized packaging.

\section{ii. Activating Body Consciousness Reduces Consumption of Larger Packaging}

A study conducted by Coelho do Vale, Pieters, and Zeelenberg (2008), also suggests that portion control packaging may not decrease consumption behaviour under certain conditions. Researchers found that larger packaging reduced consumption when participants were "activated" for self-regulatory concerns. The experiment had a 2 (large vs. small package size) x 2 (self-regulatory concerns activated vs. control) betweensubjects design and participants were randomly assigned to one of the four conditions. In the self-regulatory concerns "activated" condition, participants completed the Body Satisfaction Scale (Slade et al., 1990), the Drive for Thinness scale (Garner et al, 1983), and the Concern for Dieting scale (Herman and Policy, 1975). Next, participants were weighed and their height, hips, and waist were measured in front of a large mirror in order to elicit self-regulatory concerns. Although this study was not explicitly about dietary restraint, this body activation paradigm could be triggering to restrained eaters' familiar concerns with caloric control by exacerbating body image concerns. 
In order to conceal the true purpose of the study, all participants were then requested to view an episode of an unrelated television show and were asked to evaluate a variety of ads embedded in the video clip as filler. Participants were given either larger packages or multiple smaller packages of potato chips to eat during the television clip, but the total quantity and calorie content of potato chips remained the same.

These researchers found that when palatable treats came in larger packaging, and self-regulatory concerns were activated, consumers deliberated the most before consumption, were least likely to open the package and consume, and consumed the least amount of chips. However, activating self-regulatory concerns had no impact on consumption when treats were packaged in smaller format. The authors suggested that these findings imply that in order for self-regulation to occur, consumers need to perceive the conflict between the tempting food and hindrance of long-term goals. Small temptations may remain unnoticed in this context and therefore not elicit self-control coping mechanisms.

\section{iii. Both Diet "Manipulated" and Diet "Measured" Individuals Consume More from}

\section{Smaller Packaging}

Holden and Zlatevska (2015) replicated the key components of the Scott et al. (2008) and Coelho do Vale et al. (2008) studies. Their study was a 2 × 2 x 2 betweensubjects design. The three factors were measured diet-consciousness (e.g., high or low dietary restraint); manipulated diet-consciousness (e.g., exposure to diet prime or neutral control); and portion size (e.g., multiple small or one large package).

To measure diet-consciousness, participants simply completed the Dietary Restraint Scale (Herman \& Polivy, 1980) and divided participants into either high or low 
dietary restraint based upon a median split. To manipulate diet-consciousness, similar to Coelho do Vale et al. (2008), researchers administered the Dietary Restraint Scale (Herman \& Polivy, 1980), two items from the Dieting Questionnaire (Oliver \& Bearden, 1985), 16 items from the Body Satisfaction and Drive for Thinness subscale (Garner et al., 1983), and requested self-reported height and weight. In the neutral control condition, participants completed a "consumer activism" questionnaire during exposure to the M\&M's and completed the same dieting prime questionnaires after exposure to the M\&M's. Finally, researchers controlled package size by presenting participants with $200 \mathrm{~g}$ of M\&Ms in either four small packages $(4 \times 50 \mathrm{~g})$ or one large package $(1 \times 200 \mathrm{~g})$.

During this experiment, the Dietary Restraint Scale was used to both measure the participants' pre-existing status of dietary restraint (i.e., determine whether the participant is a restrained or unrestrained eater), and the same Dietary Restraint Scale was used to manipulate diet-consciousness (i.e., the scale was included in the questionnaire package intended to evoke feelings of diet-consciousness). As previously mentioned, during the neutral no-prime condition, the Dietary Restraint Scale was administered after the eating task. Since manipulated and measured diet-consciousness questionnaires were administered to the same participants within a similar time frame, order effects may have confounded the results of the study. In other words, 'measured' diet-consciousness was evaluated within the manipulation experimental design and this dieting activation may have heightened responses on the measured Dietary Restraint Scale. Additionally, similar to the Coelho do Vale et al. (2008) study, manipulated diet consciousness contained questionnaires relating to both body satisfaction and dieting behaviour. While these variables maybe strongly correlated, they are nonetheless separate constructs. The current 
study overcomes this confound in that it measures diet consciousness at a separate point in time and is able to parse apart body image and dieting primes.

Consistent with the previous two studies, Holden and Zlatevska (2015) found that diet-conscious individuals consumed more M\&Ms from smaller packaging versus larger packaging. Both diet "manipulated" and diet "measured" conditions found this outcome, however the effect was clearer and more pronounced when diet-consciousness was manipulated. Again, researchers suggested that diet-conscious eaters may consume more from smaller, partitioned portions compared to larger, unpartitioned portions and this effect may be more pronounced when diet-consciousness is manipulated, rather than measured. Researchers also noted that future studies should attend to why this effect exists, and refine how diet consciousness is measured.

iv. Restrained Eaters Consume Less from Large Packaging After Exposure to a Diet

\section{Prime}

A recent study conducted by Versluis and Papies (2016) also found evidence to suggest that restrained eaters may consume less when food is packaged in a larger format, after exposure to a diet-prime. These researchers conducted a two-part study. In the first experiment, participants were exposed to either a diet prime (fitness magazine) or control condition (travel magazine), and participants were requested to indicate expected consumption of various snacks. A picture of either a large or small amount of each type of snack was presented to participants. Results indicated that a diet prime reduced expected consumption of larger packaging for both restrained and unrestrained eaters compared to the control prime group. There was no effect on expected consumption from 
smaller packaging. However, this study simply assessed expected consumption behaviour. Thus, experiment two assessed actual consumption behaviour.

In experiment two, researchers provided participants with either a large bag or multiple smaller bags of M\&Ms while exposing participants to a movie clip and various commercials. In this experimental condition, commercials were about dieting/ calorie control (e.g., Weight Watchers, Dannon Light and Fit yogurt, Special K breakfast cereals, and Nike Basketball). The authors specified that the message behind each commercial was focused upon resisting tempting foods, beginning a diet, weight loss, and reaching goals. However, they also curiously considered a Nike basketball commercial to be reinforcing dieting behaviour. It is plausible that exercise and fitness behaviour may also be present in the experimental condition and potentially confounded the results of the 'diet' priming. In the control condition, commercials were unrelated to dieting and food (e.g., Ikea furniture). Results demonstrated that exposure to a diet-prime significantly reduced consumption behaviour from large packaging for restrained eaters, while unrestrained eaters were unaffected by the prime. Similar to experiment one, restrained and unrestrained eaters were not impacted by the diet prime when presented with smaller packaging. These findings corroborate that exposure to a diet-prime at the right time may remind restrained eaters of their dieting goal, and subsequently reduce consumption behaviour of large packaging (Versluis \& Papies, 2016).

\subsubsection{Theoretical Explanations of Results}

Interestingly, Scott et al. (2008) and Coelho do Vale et al. (2008) reported similar findings, but provided theoretically different explanations for the results. 
Scott et al. (2008) theorized that lapses in self-control for restrained eaters were the result of stress induced by conflicting food information. They suggested that small packages of hedonic treats were perceived as both a diet food but also a snack that is high in calories, and the uncertainty of whether or not the treat is forbidden or allowed creates "stress" (e.g., conflict due to uncertainty). A follow-up study also conducted by Scott et al. (2008) found that restrained eaters found it to be more stressful to consider thinking about eating the small food in small packages, versus the large food in large packaging. Stress concerning the food packaging was operationalized by completing a question on a 7-point scale (disagree/agree), stating, "It is stressful to think about eating the M\&Ms." These findings suggest preliminary evidence for the concept that smaller tempting foods in small packaging may produce conflict stress for restrained eaters. Given that the restrained eaters are already in a vulnerable, depleted state from dieting, and are prone to overeating when feeling anxious, researchers proposed that the conflict stress of not knowing whether the food meets their criteria may result in an increased consumption from the smaller packages. While Scott et al. (2008) theorized that perceived conflict stress results in increased consumption of smaller treats, Coelho do Vale et al. (2008) conversely theorized that restrained eaters don't notice the self-control conflict surrounding smaller, yet hedonic, foods (a phenomenon known as the "Flying Under the Radar Effect").

\section{Flying Under the Radar Effect}

In order for self-regulatory behaviour to occur, consumers must feel and be aware of the self-control conflict. In other words, the individuals must be conscious that the food product is both tempting and simultaneously acknowledge that consumption would 
interfere with overarching goals (Fishback \& Shah, 2006; Trope \& Fishbach, 2000). The Flying Under the Radar Effect stipulates that small inconspicuous indulgences do not elicit self-control conflict, nor do they activate coping mechanisms, and thus go unnoticed and "fly under the radar" of the individual's long-term goals (Coelho do Vale et al, 2008). When a product is presented in a small, single-serving sized portion, the consumer may deem the product as "acceptable" and therefore would not activate any coping mechanisms that inhibit consumption behaviour. Likewise, restrained eaters also perceive "99-calorie" packages to be perceived as a healthier food option (Payne et al., 2014). Conversely, when a product is presented in a larger size, the consumer may deem the product as "unacceptable" and activate the corresponding coping mechanisms to manage their intake. In this theory, portion control packaging of tempting products may cause consumers to let their guard down and actually increase energy intake, contrary to the product's intended goal.

Furthermore, when multiple smaller packages are available, the consumer may infer that the package itself can inhibit consumption (e.g., the package acts as an external control), and in turn, this may mean that certain types of consumers rely on the packaging to inhibit consumption, and do not elicit their own coping mechanisms. The smaller size packaging may act as a "substitute" for eliciting self-control, however, this strategy may not be effective at inhibiting consumption behaviour. Obviously, the package size can only limit the serving size, however it cannot limit the number of packages consumed, and thus this packaging format may backfire and increase consumption under certain conditions (Argo \& White, 2012). Thus, Coelho do Vale et al. (2008) theorized that individuals do not elicit self-control conflict when the packaging is small, and smaller 
packages "fly under the radar" of the individual's long-term goals, resulting in increased consumption of smaller packaging.

Versluis and Papies (2016) found that restrained eaters consume less food from larger packaging after exposure to a dieting prime (compared to no diet prime). However, researchers did not find that a diet prime increased intake of smaller packaging. These researchers suggested that individuals consume less from larger packaging after exposure to a dieting prime due to goal priming. Since restrained eaters are motivated to diet, priming or reminding participants of their dieting goals can help individuals control intake with large quantities of snacks and thus, external cues can generate behaviour consistent with the individual's goals.

\subsection{The Current Study}

Diet or body image primes may be effective at reducing consumption behaviour for restrained eaters when presented with food packaged in a larger format. However, previous research assessing these effects may have had confounded primes. Specifically, the methodology implemented by Coelho Do Vale et al. (2008) activated self-regulatory concerns by requesting participants complete the Body Satisfaction Scale, the Drive for Thinness scale, the Concern for Dieting scale, and weighing/measuring participants in front of a large mirror. However, the combination of these measures is typically assessing and activating two separate constructs: body image concerns and concern with dieting. Furthermore, Scott et al. (2008) may have inadvertently activated participants for dietary concerns by requesting they complete the Restrained Eating Scale. Finally, Versluis and Papies (2016) simply primed participants for dieting behaviour, and ostensibly did not assess body image primes. However, this study also may have inadvertently amalgamated 
the two primes by having images of bodies present in the dieting and calorie controlling commercials. It is reasonable to assume that the Weight Watchers commercial and Nike Basketball commercial likely contained bodies that would trigger body image concerns. Thus, previous research that evaluated the effects of body image or dieting primes on the partitioning paradox has confounded primes. The present study aims to parse apart these constructs and determine which prime, dieting or body image, has the greatest effect on the partitioning paradox.

Therefore, the present study aims to better understand why and under what conditions the Flying Under the Radar Effect exists. As previously mentioned, the methodology implemented by Coelho Do Vale et al. (2008), Scott et al. (2008), and Versluis and Papies (2016) may have inadvertently activated self-regulatory concerns by probing participants for both body image and dieting concerns, together. The current study aims to parse apart these two constructs and identify if probing participants for body image or dieting concerns, separately, contributes to the partitioning paradox. We are interested in investigating a well-controlled replication, in addition to accounting for these more fine-grained issues.

Additionally, the present study aims to assess the interaction effects of restrained eaters and priming participants for (1) body image or (2) concern for dieting. Specifically, restrained eaters not activated for either body image or concerns for dieting are more likely to deem smaller packaged-sized treats as "acceptable" and thus not activate any coping mechanisms to manage their intake. Therefore, we hypothesize that restrained participants in this condition will consume more treats in smaller packaging. Conversely, restrained eaters activated for body satisfaction and concern for dieting will 
deem larger packaging as "unacceptable" and thus reduce consumption for food in this format.

\section{Hypotheses}

We hypothesize that there will be a three-way interaction between restraint status, package size, and prime condition.

H1: Restrained eaters activated for either body image concerns or dietary concerns will consume less food from larger packaging and increase consumption for small packaging.

Specifically, Restrained eaters activated for either body image concerns or dietary concerns will consume less food from larger packaging compared to a control condition with no prime (e.g., restrained eaters will be conscious that the product interferes with long-term goals, and thus consume less). That is, we expect to replicate the findings from Versluis and Papies (2016).

Similar to Scott et al. (2008) and Holden and Zlatevska (2015), we also anticipate that restrained eaters activated for either body image concerns or dietary concerns will increase consumption for small packaging compared to large packaging (e.g., the portioning paradox).

Although we believe that both experimental conditions (e.g., body image activation and dietary concern activation) will consume less food from larger packaging compared to the control condition, we do not have a specific hypothesis on which experimental condition will result in the least amount of food consumed of if there will in fact be a difference (e.g., exploratory hypotheses assess the difference between body image concerns and concern for dieting activation). 
H2: Unrestrained eaters will be unaffected by the body image and diet primes for smaller packaging. We hypothesize that unrestrained eaters will consume more from larger packaging and less from small packaging. 


\section{Methods}

\subsection{Participants}

Participants were 286 undergraduate students enrolled in introductory psychology courses at Ryerson University in Toronto, with a majority of subjects $(77.6 \%, n=222)$ identifying as female (males, $21.3 \% n=61$, other/wish not to disclose gender, $1.0 \%, n=$ 3). Additional demographic characteristics of the sample are provided in the results section. All participants were recruited using a web-based undergraduate participant pool from SONA systems, and they participated in exchange for partial course credit (1\%). The study title was deceptively advertised as, "Physical and Psychological Factors in Consumer Preferences" and participants were informed that the study was examining how physical and psychological variables may relate to consumer preferences. This deception was utilized because if participants were made aware of our actual hypotheses, they may be influenced to modify their eating habits, and thus confound the results of the study.

\subsection{Measures and Materials}

The study design is a $2 \times 2 \times 3$ between-subjects design. The three factors are restraint status (restrained vs. unrestrained eaters), package size (multiple small packages vs. one large package), and prime exposure (body image prime, diet prime, and control prime).

Revised Restraint Scale (RS; Herman et al., 1980; See Appendix A). The RS is a 10-item questionnaire that measures participants' intent to restrict food intake with the goal of weight loss and efforts and effects related to dieting. The scale is comprised of two subscales: Dieting Behaviour and Weight Fluctuation (e.g., "How conscious are you 
of what you are eating?"; "What is the maximum amount of weight you have ever lost within 1 month?"; See Appendix A). Items are rated on 4- or 5- point Likert scales, and total scores range between 0 and 35 . Higher scores indicate higher levels of dietary restraint, with the typical cut-off score being 15 (Herman \& Polivy, 1980; Polivy, Heatherton, \& Herman, 1988; Kemps et al., 2016). Previous research has found that the scale has good internal consistency in normal-weight samples (Cronbach's alpha $=.81$; van Strien et al., 2007). The Cronbach's alpha with the current study sample was excellent $(\alpha=$.92.). Furthermore, the scale has significantly correlated with alternate measures of dietary restraint (Laessle, Tuschl, Kotthaus, \& Pirke, 1989), suggesting that the scale is a valid measure of restraint status.

Demographic Questionnaire. The demographic questionnaire is a brief questionnaire that asks respondents to report their age, gender, and race/ethnic background (see Appendix B).

Body Mass Index (BMI). BMI was calculated from experimenter-measured height and weight in a laboratory setting. Participants were wearing indoor clothing and stocking feet. Weight was measured on an analog, spring scale and height was measured using a fixed measuring tape. BMI $\left(\mathrm{kg} / \mathrm{m}^{2}\right)$ was calculated by dividing weight (in kilograms) over height (in metres squared).

Package Sizes. Participants were randomly assigned to one of two M\&M portion groups: (1) multiple units of M\&Ms in small packaging, or (2) the same amount of M\&Ms in one large package. Both conditions contained 230 individual M\&M's. In the small package group, 230 M\&M's were divided into 15 small packages (ten packages of 15 M\&M's and five packages of 16 M\&M's per bag), similar to the M\&M packages 
marketed as "fun-sized" (approximately 60 calories per bag, exactly 1150 calories total). In the large package group, all 230 M\&M's were in one package, similar to the marketed "take home size" package (1150 calories total). See Appendix D for pictures of packages.

Priming Conditions. Participants were randomly assigned to one of three conditions. The two experimental conditions primed for either body image concerns or dieting concerns, and there was a third neutral condition. These primes were accomplished through the completion of thirty items taken from existing valid and reliable questionnaires, and completion of a behavioural task.

Condition 1: Body Image Prime. Participants in this group had body image concerns primed by completing body image items from various questionnaires, and by being exposed to primes shown in past research to elevate body image concerns. Participants randomly assigned to the body image prime condition completed a 30-item questionnaire, which is comprised of items taken from the 16-item Body Satisfaction Scale (Slade et al., 1990), the 23-item Body Parts Satisfaction Scale (Berschied et al., 1972), and the 34-item Body Shape Questionnaire (Cooper et al., 1987; See Appendix E). The questions selected from each scale were chosen based on their face validity to increase participants' body awareness, and ultimately prime body image concerns. Sample items include: "I think that my stomach is too big" and "Has seeing your reflection (e.g., in a mirror or shop window) made you feel bad about your shape?" Upon completing these items, participants next had body size measurements taken, including weight, height, and circumference measures of their hips and waist. In order to further activate body image concerns, measurements were conducted in front of a large, fulllength mirror. 
Condition 2: Diet Prime. Participants in the second experimental group had dieting behaviour and dietary concerns activated. Similar to Condition 1, participants completed a questionnaire and partook in a behavioural task in order to activate the diet prime. Participants completed a thirty-item questionnaire, with items taken from the 3item Current Dieting Questionnaire (CDQ; Lowe, 1993), the 7-item Drive for Thinness scale (Garner et al, 1983), the 51-item Three-Factor Eating Questionnaire (Stunkard \& Messick, 1985), and the 10-item Bratman Orthorexia Scale (Bratman \& Knight, 2000; See Appendix H). Sample items from the diet prime questionnaire include: "I deliberately take small helpings as a means of controlling my weight" and "I have a pretty good idea of the number of calories in common food." In the behavioural section of the diet prime condition, participants were then asked to evaluate aspects of common products that have been pitched to consumers as diet food (President's Choice ${ }^{\mathrm{TM}}$ "Blue Menu" items), including expected nutritional and caloric content, and its usefulness in weight control (e.g., "If I use this product, it will be easier for me to stay on a diet"; See Appendix G). Participants could visually inspect and hold the packaged products but not taste them.

Condition 3: Control Condition Prime (Political Affiliation). Participants in the control group completed a thirty-item questionnaire unrelated to body image or dietary concerns. For this neutral condition, we asked questions about mildly controversial political attitudes (e.g., "Should postsecondary education be a provincial or federal responsibility?"; See Appendix H) and participants were then asked to evaluate the political logos of a fictitious politician running in an election (see Appendix I). 


\subsection{Procedure}

Please see Appendix C for a flowchart and visual representation of the study's procedure.

The Revised Restraint Scale was completed online, at least 24 hours prior to the participant entering the laboratory. This was an attempt to correct a confound present in previous research of simultaneously measuring and manipulating concern with dieting (provide citations) Given that completing a scale on dietary restraint could influence eating behaviour and/or reveal the true hypotheses of the study, it was essential that we determined participants' level of restraint at a separate time from the laboratory portion of the study. Thus, only participants who completed the RS in advance were eligible to participate in our laboratory study.

Interested participants were invited to the Health and Sport Psychology Laboratory at Ryerson University, and were tested individually during a one-hour session. Participants arrived at our lab, where the researcher explained that the study examined how physical and psychological variables may relate to consumer preferences, and that we were asking participants to complete a few questionnaires, give simple physiological measurements (e.g., heart rate, body size), and assess commercial products (e.g., M\&M candies). In order to reduce the likelihood of participants modifying their eating behaviour, participants were not made aware in advance that researchers were actually measuring consumption of the candies. Participants then provided written consent to participate (see Appendix J).

After providing consent, all participants completed a basic demographic questionnaire (see Appendix B) and then were randomly assigned to one of three 
conditions. As outlined in above, participants were assigned to either be primed for body image concerns, dieting concerns, or a body-neutral control. All conditions entailed participants completing a thirty-item questionnaire (e.g., items surrounding body image, dieting, or political affiliation) and an active task (e.g., weighed/measured in front of full length mirror, evaluated a diet product, or evaluated a political logo).

Participants randomly assigned to the body image prime condition provided height and weight measurements during the 'priming' phase of the study, prior to completing the eating task. Participants in the remaining two conditions (dieting prime and control) provided these measurements at the very end of the study, after completing the eating task. Please see the diagram in Appendix C for clarity. We measured participants at the beginning of the body image prime in order to elevate body image concerns. We chose to measure participants in the diet and control conditions at the end of the study in order to get accurate measurements of BMI, however to not activate feelings of body consciousness prior to eating the candies and thus, confound the primes.

After this "priming" stage we measured the heart rate of all participants (measured by assessing the pulse at the wrist) and we advised them that we would measure this again in 15 minutes. The rationale behind measuring heart rate was twofold. One is to keep with the cover story that our study considers physical influences on consumer behavior, and it also provides a reason for participants to remain in the lab for a set amount of time while they have access to food (M\&M's) for snacking. The measure of food consumed is one of the main outcome measures in the study and this methodology allows researchers to control for the amount of time that food is available. 
Next, all participants were told that we were interested in their evaluations of five consumer products (chocolates, a unisex sweater, a car, and two travel magazines) that were assessed via questionnaires (see Appendix K). The first product to be presented was always the chocolate, and all participants were told that they are welcome to eat as much as they want, but we requested that the M\&M packaging didn't leave the room as we "didn't have permission to distribute it". Unbeknownst to the participants, they were randomly assigned to one of two M\&M portion groups: (1) multiple units of M\&Ms in small packaging, or (2) the same amount of M\&Ms in one large package. If participants completed their consumer preference questionnaire before 15 minutes has expired they were asked to wait alone in the testing room (based on the heart rate cover story).

Our variable of interest was the amount of chocolate consumed. After the participant had completed the study and left the lab, the amount of chocolate consumed was determined by hand counting how many chocolates were remaining, and subtracting that number from 230 (total amount of M\&M's given).

In order to confirm that the participants did not identify the hypothesis of the study, participants were then asked an open-ended question determining what they thought the purpose of the research was. Participants were then fully debriefed, including an explanation and rationale of why we used a deceptive 'cover story'. All participants were given an opportunity to ask questions and express any concerns. Finally, all participants were provided with a written debrief handout (see Appendix L).

\section{Data Preprocessing}

Data from the restraint questionnaire were downloaded from the SONA system, while the laboratory-completed questionnaires were downloaded from Qualtrics into the 
Statistical Package for the Social Sciences (SPSS; version 23). These two datasets were merged for analysis.

A total of 302 participants participated in the experiment, however several were excluded from final analyses for various reasons. We excluded 9 participants because they were able to correctly identify that the study was about the amount of M\&M's consumed: 3 participants did not complete the Revised Restraint Scale (e.g., they submitted a blank or unusable survey): 2 participants were removed because they selfdisclosed that their diabetes prevented them from eating the M\&M's: 1 participant was removed due to physical disabilities that prevented them from self-feeding and 1 participant removed the M\&M packaging from the room so it was unavailable for counting. Upon removing these individuals from the dataset, 286 participants were included in the analysis.

\section{Power analysis}

A power analysis was conducted using $\mathrm{G}^{*}$ Power 3.1 software to determine the sample size required for the ANOVA analyses to obtain significant effects for the 12 groups ( 6 conditions for restrained/unrestrained eaters). The power analysis was conducted using an effect size $f=0.25$, an error probability of $\alpha=.05$, and a power of 1$\beta=.80$. Upon inputting these parameters, the power analysis determined that a minimum of 251 participants would be required to detect the three-way interaction effect, if one exists. 


\section{Results}

\section{Descriptive Statistics}

A total of 286 participants provided complete and usable data for the study.

Participants ranged in age from 17 to $52(M=20.20, S D=4.89)$, and the sample was ethnically diverse (i.e., 32.5\% White, 32.1\% Chinese, Korean, South and Southeast Asian, 10.5\% Filipino, 4.9\% Black, 4.8\% Arab and West Asian, and 3.1\% Latin American). BMI ranged from 15.36 to $43.00(M=22.61, \mathrm{SD}=4.02)$. See Table 1 for demographic information. 


\section{Table 1}

\section{Demographic Characteristics}

\begin{tabular}{|c|c|}
\hline Characteristic & $(N=286)$ \\
\hline Age & $20.20(4.89)$ \\
\hline BMI & $22.61(4.02)$ \\
\hline Ethnicity (\%) & \\
\hline Arab, West Asian & 4.8 \\
\hline Black & 4.9 \\
\hline Chinese, Korean, & 32.1 \\
\hline South \& Southeast & \\
\hline Asian & \\
\hline Filipino & 10.5 \\
\hline Latin American & 3.1 \\
\hline White & 32.5 \\
\hline Other & 9.8 \\
\hline Missing Data & 2.1 \\
\hline
\end{tabular}




\section{Gender}

Consistent with past research on package size, body/diet primes, and consumption behaviour, the present sample was not stratified by gender. Although females $(M=$ 26.74) ate more $M \& M$ 's than males $(M=19.74)$, a t-test revealed that this result was not statistically significant $(p=.051)$. Furthermore, removing males from the data set did not have an appreciable effect on the outcomes of the study. Thus, both males and females were treated equally in final analyses.

\section{Consumption Behaviour (M\&M's Eaten)}

A majority of participants ate at least one M\&M (90.2\%). Participants ate between 0 and 136 of the available 230 M\&M's in the fifteen minutes allotted $(M=$ 25.31, $S D=23.12)$. The modal number of M\&M's eaten was $15(n=36,12.6 \%)$, which suggests that most participants ate 1 small package of M\&M's and then stopped eating.

\section{Dietary Restraint Categorization}

Participant scores ranged from 0 to 30 on the RS $(M=11.86, S D=5.34)$.

Previous research on the RS has typically favored the use of a cut-off score for classifying restraint status, rather than median split categorization of the continuous score. Primary research on the RS has recommended a score of $\geq 15$ to classify an individual as a restrained eater and a score of $\leq 14$ to classify an individual as an unrestrained eater (Herman \& Polivy, 1980; Polivy, Heatherton, \& Herman, 1988). Using these cut off scores in the present sample, $31.3 \%$ of participants would be classified as a restrained eater, whereas $68.7 \%$ would be classified as an unrestrained eater.

However, the present study has been developed based on previous research conducted by Scott et al. (2008), Holden and Zlatevska (2015), Coelho Do Vale et al. 
(2008) and Versluis and Papies (2016). The former three studies all used a median split to categorize dietary restraint and Versluis and Papies (2016) defined "high dietary restraint" as $1 \mathrm{SD}$ above the mean and "low dietary restraint" as $1 \mathrm{SD}$ below the mean. For comparison purposes to these critical studies, we have also chosen to conduct a median split, and thus, all participants with a score of 12.00 and above were classified as restrained eaters, and participants with a score below 12.00 were classified as unrestrained eaters. It is important to note however, that any method of classifying dietary restraint (using a cutoff score, using $1 \mathrm{SD}$ above and below the mean, and conducting a median split) in these analyses yielded similar findings.

\section{Correlational Analyses}

Pearson's correlations were computed between all continuous study variables to examine the relationship among variables. There was a significant correlation between the continuous dietary restraint score and BMI, $r=.435, p=.000$. As expected, these results indicate that higher BMI's are correlated with higher tendencies to be a restrained eater. See Table 2.

Furthermore, point-biserial correlational analyses were conducted between nominal and continuous variables. There was a significant correlation between gender and BMI, $r=.163, p=.006$ (being male was associated with a higher BMI). There was also a significant correlation between the median split dietary restraint score and BMI, $r$ $=.350, p=.000$, which also reveals that higher BMI's are correlated with restrained eaters. See Table 3. 
Table 2

Bivariate Correlational Analyses between Continuous Variables

\begin{tabular}{lccc}
\hline & BMI & $\begin{array}{c}\text { M\&Ms } \\
\text { Eaten }\end{array}$ & $\begin{array}{c}\text { Restraint }- \\
\text { Continuous }\end{array}$ \\
\hline 1. BMI & 1.00 & -.068 & $.435^{* *}$ \\
2. M\&Ms & & 1.00 & -0.36 \\
Eaten & & &
\end{tabular}

3. Restraint -

1.00

Continuous

$* * p<.001$ 
Table 3

Point Biserial Correlational Analyses between Nominal and Continuous Variables

\begin{tabular}{|c|c|c|c|}
\hline \multicolumn{3}{|c|}{ Number of M\&M'S } & \multirow{2}{*}{\begin{tabular}{c}
\multicolumn{1}{c}{ Restraint - } \\
Continuous Score
\end{tabular}} \\
\hline & $\underline{\text { Eaten }}$ & $\underline{\mathrm{BMI}}$ & \\
\hline 1. Gender & -.112 & $.163 * *$ & -.070 \\
\hline 2. Package Size & .070 & -.018 & .057 \\
\hline 3. Restraint - & -.056 & $.350 * *$ & $.807 * *$ \\
\hline \multicolumn{4}{|l|}{ Median Split } \\
\hline 4. Body Image & -.048 & -.043 & .000 \\
\hline \multicolumn{4}{|l|}{ Prime Condition } \\
\hline 5. Diet Prime & -.037 & .056 & -.065 \\
\hline \multicolumn{4}{|l|}{ Condition } \\
\hline 6. Control Condition & .084 & -.012 & .065 \\
\hline
\end{tabular}




\section{Effects of Dietary Restraint, Package Size, and Prime Condition on Snack Consumption Behaviour}

We hypothesized that there will be a three-way interaction between restraint status, package size, and prime condition. A $2 \times 2 \times 3$ between groups ANOVA was used to compare restraint status (restrained vs. unrestrained), package size (small vs. large) and prime condition (body image vs. diet vs. control) on amount of M\&M's consumed.

Contrary to our main hypothesis (H1), the three-way interaction effect between restraint status, prime condition and package size was not significant on the amount of M\&M's consumed, $F(2,274)=.733, p=.481, \eta^{2}=.005$.

The main effect of restraint status on the amount of M\&M's consumed was not significant, $F(1,274)=.930, p=.336, \eta^{2}=.003$. The main effect of package size on the amount of M\&M's consumed was not significant, $F(1,274)=1.363, p=.244, \eta^{2}=.005$. Furthermore, the main effect of prime condition (diet, body image or control) on the amount of M\&M's consumed was not significant, $F(2,274)=1.193, p=.305, \eta^{2}=.009$.

There were also no significant interaction effects. Contrary to H2, the two-way interaction effect between restraint status and package size was not significant on the amount of M\&M's consumed, $F(1,274)=.001, p=.982, \eta^{2}=.000$. The interaction effect between restraint status and prime condition was not significant, $F(2,274)=.511$, $p=.601, \eta^{2}=.004$. The interaction effect between prime condition and package size was not significant, $F(2,274)=.313, p=.732, \eta^{2}=.002$.

Although participants ate less overall in the diet prime $(M=23.95, S E=2.42)$ and body image prime condition $(M=23.60, S E=2.40)$ compared to the control condition $(M=28.29, S E=2.38$; See Table 4), a t-test revealed that the difference between the 
experimental conditions (collapsed together) and the control condition was not statistically significant, $\mathrm{t}(284)=-1.42, p=.157$.

Similarly, although participants ate less overall in the small package condition ( $M$ $=23.66, S E=1.94)$ compared to the large package condition $(M=26.89, S E=1.97)$, the difference between the package size conditions were not statistically significant, $p=.244$.

Finally, although restrained eaters ate fewer M\&M's overall $(M=23.94, S E=$ 1.95) compared to unrestrained eaters $(M=26.61, S E=1.97)$, the difference in amount of M\&M's consumed between restrained and unrestrained eaters was not statistically significant, $p=.336$. 
Table 4

Dietary Restraint, Package Size, and Prime Condition on Snack Consumption Behaviour

\begin{tabular}{|c|c|c|c|c|c|}
\hline Prime & Package & Restraint & & Std. & \\
\hline Condition & Size & Status & Mean & Deviation & $N$ \\
\hline \multirow[t]{4}{*}{ Diet } & Small & Unrestrained & 18.22 & 17.51 & 23 \\
\hline & & Restrained & 23.67 & 18.23 & 24 \\
\hline & Large & Unrestrained & 28.70 & 24.56 & 27 \\
\hline & & Restrained & 25.20 & 29.23 & 20 \\
\hline \multirow[t]{4}{*}{ Body Image } & Small & Unrestrained & 25.50 & 18.27 & 28 \\
\hline & & Restrained & 18.68 & 14.60 & 22 \\
\hline & Large & Unrestrained & 24.85 & 25.47 & 20 \\
\hline & & Restrained & 25.38 & 30.31 & 26 \\
\hline \multirow[t]{4}{*}{ Control } & Small & Unrestrained & 31.18 & 24.92 & 22 \\
\hline & & Restrained & 24.73 & 14.93 & 26 \\
\hline & Large & Unrestrained & 31.23 & 26.77 & 22 \\
\hline & & Restrained & 26.00 & 27.93 & 26 \\
\hline
\end{tabular}

Dependent Variable: Number of M\&M's Eaten 


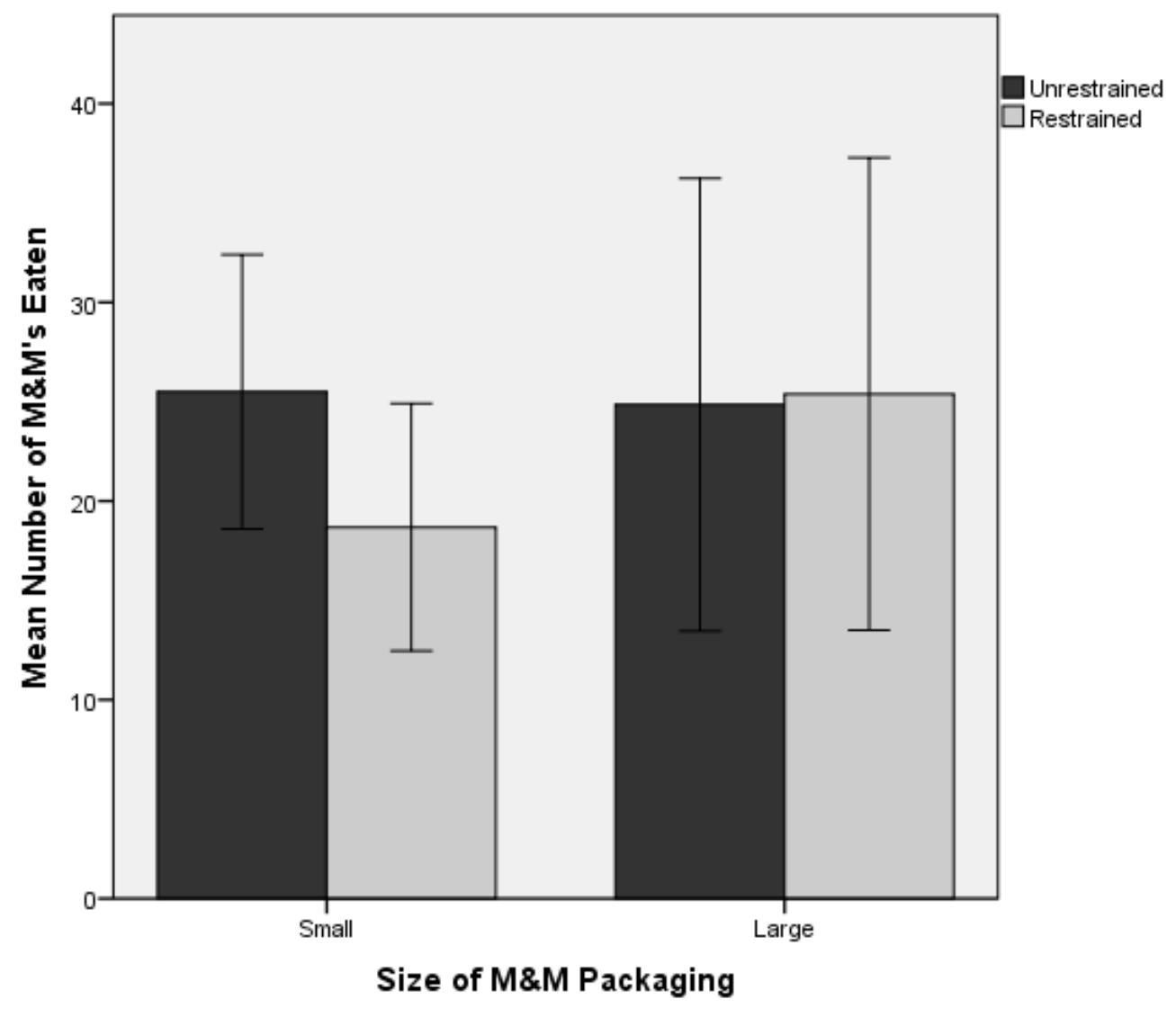

Error Bars: +/- 2 SE

Figure 1. Consumption Behaviour in Body Image Prime Condition 


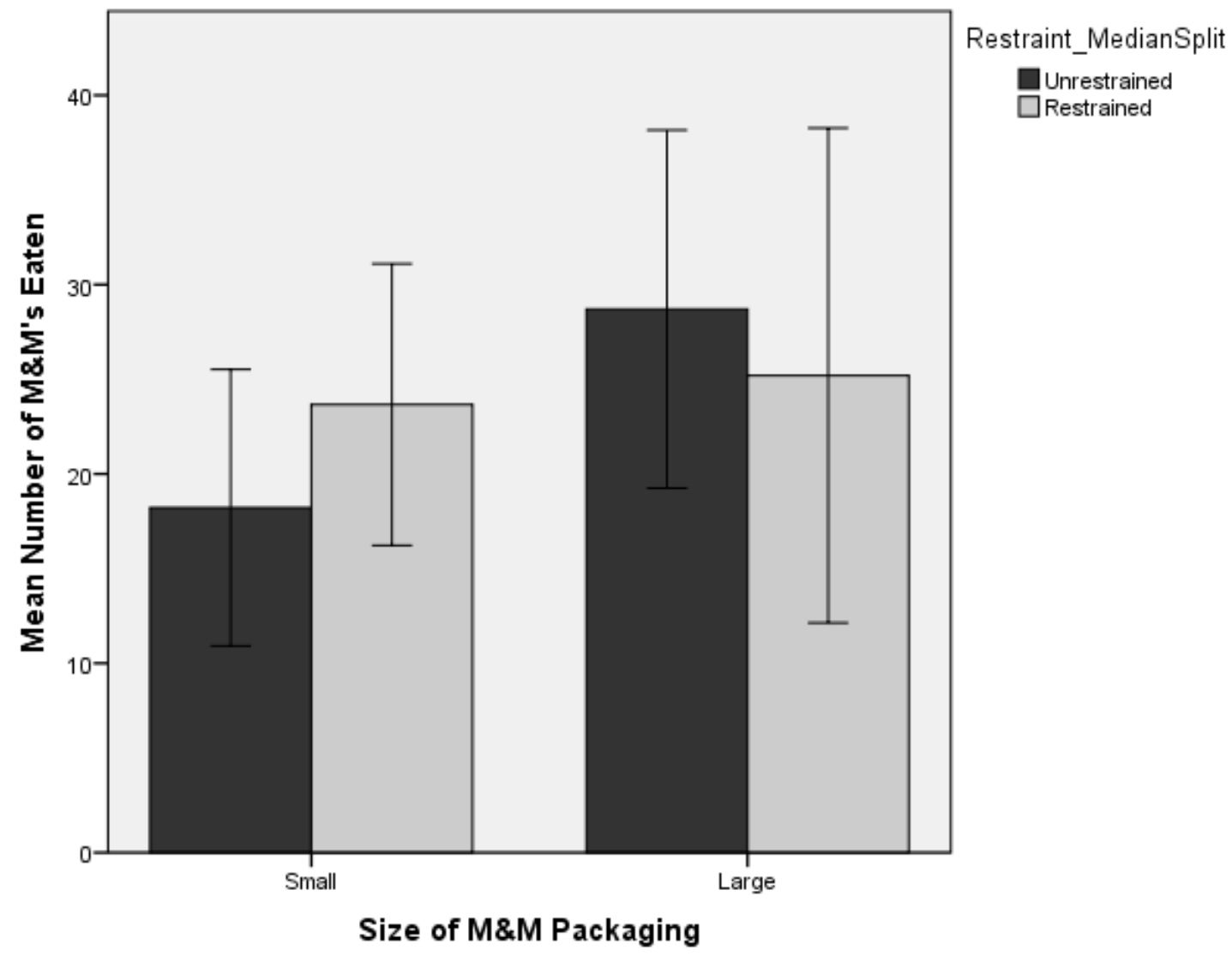

Error Bars: +/- 2 SE

Figure 2. Consumption Behaviour in Diet Prime Condition 


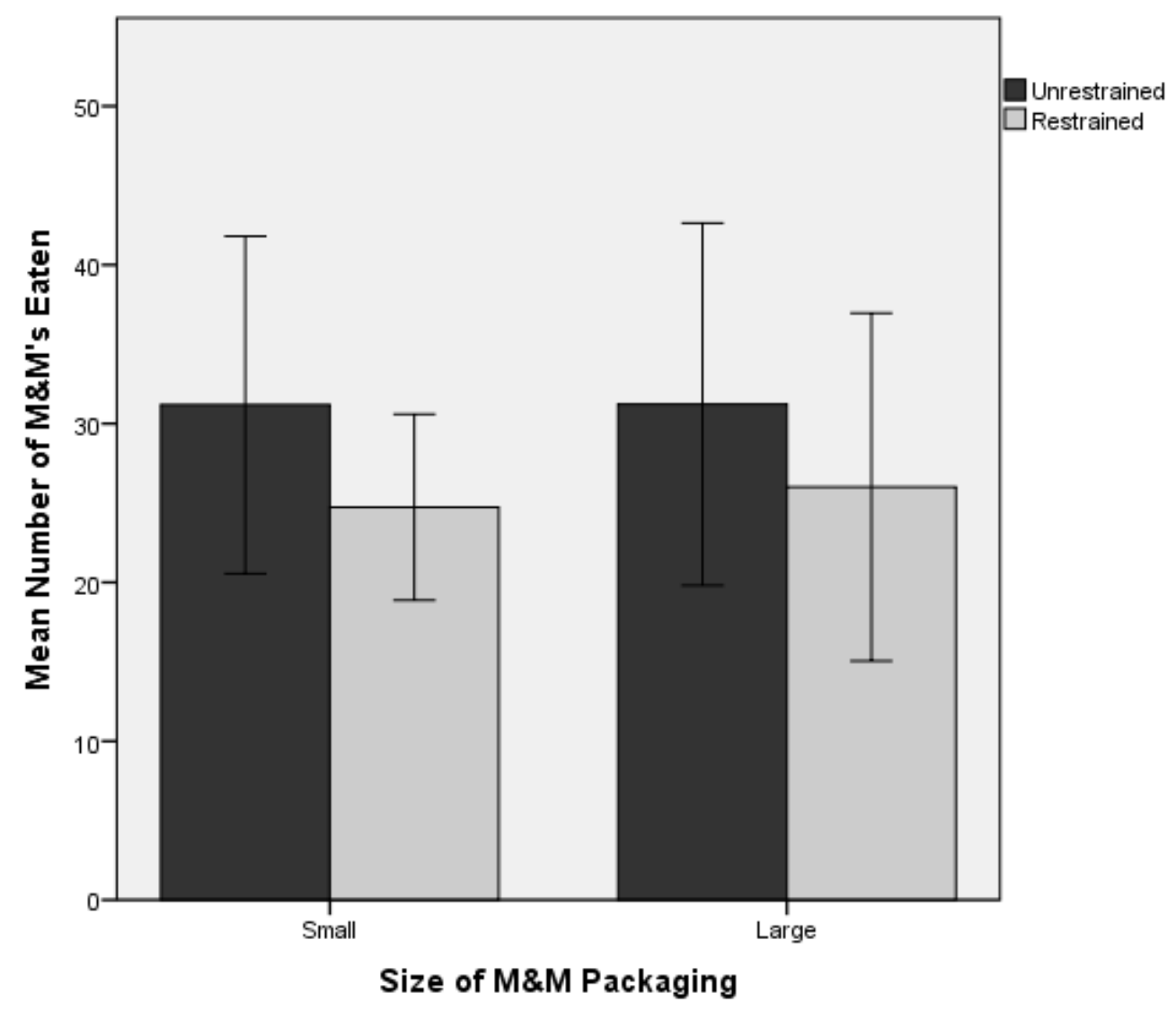

Error Bars: +/- 2 SE

Figure 3. Consumption Behaviour in Control Condition 


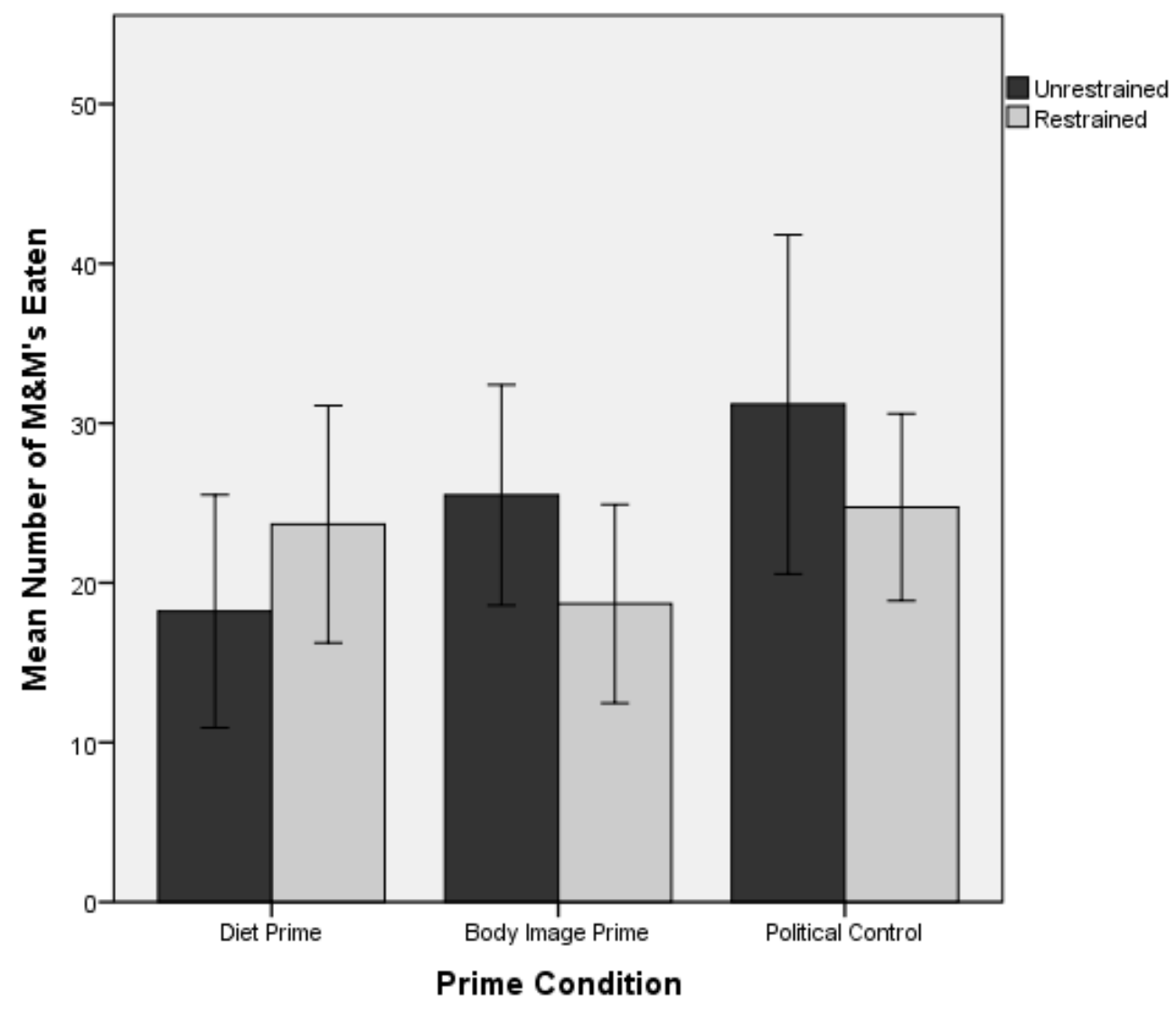

Error Bars: +/- 2 SE

Figure 4. Consumption Behaviour in Small Packaging Across Prime Conditions 


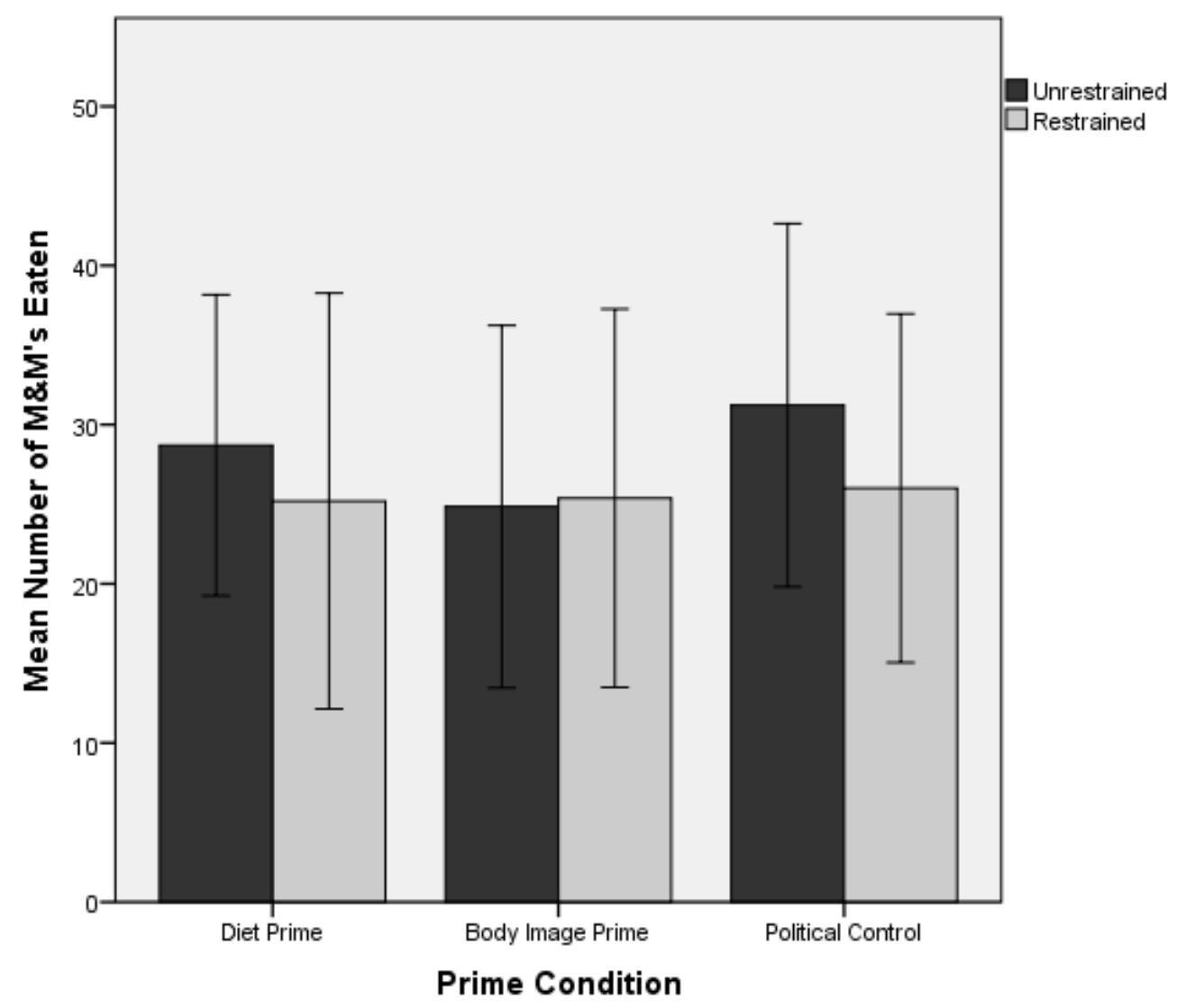

Error Bars: +/- 2 SE

Figure 5. Consumption Behaviour in Large Packaging Across Prime Conditions 


\section{Discussion}

The present study assessed the role of dietary restraint, package size, and various primes (body image vs. diet) on snack consumption behaviour. Contrary to hypotheses, restrained eaters activated for body image and/or dietary concerns did not consume less food from larger packaging and they did not consume more food from smaller packaging compared to a control condition. Similarly, contrary to hypotheses, unrestrained eaters did not alter their consumption behaviour after adjusting for package size or priming condition. In this sample, restrained and unrestrained eaters were unaffected by experimental manipulations. There are a few theoretical reasons as to why these results were not what researchers anticipated.

One potential explanation for our results differing from previous research is that our "small" package size was substantially smaller than the previous studies. Specifically, Scott et al. (2008) and Holden and Zlatevska (2015) presented 1 large bag of 200g M\&M's, and 4 small bags of 50g of M\&M's. Furthermore, Coelho Do Vale et al. (2008) presented 2 bags of $200 \mathrm{~g}$ of potato chips in the large condition, and 9 bags of $45 \mathrm{~g}$ of potato chips in the small condition. Finally, Versluis and Papies (2016) offered 1 bag of $400 \mathrm{~g}$ of M\&M's in the large condition and 1 bag of 200g M\&M's in the small condition. A 400g bag of M\&M's is advertised as a "bowl-sized" package and the amount of M\&M's in this package is equivalent to 10 serving sizes and 2300 calories. It is important to consider that this large package may be inappropriately large. The number of calories in the large packaging is comparable to an average 19 to 30 -year-old Canadians' daily recommended calories (Government of Canada, 2011), and thus is it feasible to consider that participants did not want to open such a large package. 
The current study offered one 200g bag of M\&M's for the large condition, and fifteen 13g bags of M\&M's for the small condition. The size of these packages of M\&M's were chosen to be more ecologically valid than the previous studies, and thus better able to be generalized to real world settings. The small 13g bags of M\&M's were created to emulate the advertised "fun-sized" packages of M\&M's, and the 200g large bag of M\&M's were intended to replicate the advertised "take-home size" packages of M\&M's. We chose to copy the "fun-sized" package for our small condition, as it is the packaging that is sold and available in Canada that is closest to 100-calories (which is a popular caloric number for partitioned packages; Thompson, 2006). Thus, our small packaging contained 60 calories per bag, whereas the previous studies that used $50 \mathrm{~g}$ packages which contained 287.5 calories per bag. Given that our small condition packaging is substantially smaller than the previous studies, it is possible that this modification was accountable for altering snack consumption behaviour in the small packaging conditions.

It is conceivable that participants in the small condition (regardless of "small" package size), simply opened one or two small packages, and then finished the package. In the previous studies, their "small" package would have been much larger than the current study's, and thus resulted in increased consumption. This theory is supported by the statistical tests run on our participants in the small package group. Of the 91 participants who were exposed to small packaging, the modal number of M\&M's eaten was 15 , which is equivalent to one package. Furthermore, $51.1 \%$ of participants in the small package condition opened one or two packages and subsequently finished each pack (34.5\% ate one package, $16.6 \%$ ate two packages). It is possible to conclude that 
exposure to small packaging for restrained eaters results in a "finish the pack" effect, and greater confidence is given to the package (rather than the individual) to restrict consumption for smaller packaging. This theory is contrary to the ideas that restrained eaters may subsequently eat more from smaller packaging, but rather that they trust the small packaging to restrict their intake, which may backfire when the "small" package is too large.

"Finish the pack" effect or "plate-cleaning" can be defined as eating a portion size in its entirety (Fay et al., 2011). Previous research has suggested that portion sizes may provide a social norm that invites individuals to clean their plates, and thus large portion sizes may explain why individuals consume more food (Chandon \& Wansink, 2012; Wansink, 2007). Robinson, Aveyard, and Jebb (2014) found that higher BMIs were associated with an increased tendency to clear one's plate. There is currently insufficient research surrounding dietary restraint and plate-cleaning, however the tendency for dietary restraint and BMI to be positively correlated suggests that perhaps restrained eaters are more likely to finish one's portion in its entirely. Further research to explore this theory is required.

Another interesting point to consider was the study's differences in the filler tasks while exposed to the food. Scott et al. (2008) and Holden and Zlatevska (2015) both had participants complete unrelated questionnaires while exposed to the snacks. Conversely, Coelho Do Vale et al. (2008) and Versluis and Papies (2016) exposed participants to a movie clip or a television clip (with ads) and had participants rate various aspects of the media clips with snacks present in the room. The present study's filler task had individuals rate various products on a questionnaire. The participants rated the M\&M's, a 
sweater, a photo of a car, and two travel magazines. These items were chosen as to keep the participant busy, while also not prompting any focus towards the body. However, it is possible that our filler task was too mindful and actually distracted from eating. Anecdotally, many participants spent a great deal of time and attention into completing the open-ended questions on the task and many participants also wished to discuss the travel magazines in further detail because they enjoyed browsing through them during the experiment. It is feasible to consider that the partitioning paradox only occurs during mindless tasks. However, further research is needed to explore this possibility and future directions may include comparing mindless and mindful filler tasks.

Our sample also differed quite significantly on the number of participants who ate at least one M\&M compared to the previous studies. In our filler task, we asked individuals to rate how much they enjoyed the taste of M\&M's (but they were not required to eat any candies). This question may have prompted more participants to open a package to begin eating, compared to the other studies. Holden and Zlatevska (2015) found that $57.4 \%$ of participants did not eat any M\&M's and Versluis and Papies (2016) similarly found that $59 \%$ of participants did not eat any M\&M's. Coelho Do Vale et al. (2008) found that $47.9 \%$ of participants did not open the bag of potato chips. These numbers differ quite significantly from the present sample, which found that only $9.8 \%$ of participants ate no M\&M's. The previous studies had a high instance of individuals who consumed no food and thus, researchers likely had a basement effect and nonnormal data. This could have potentially led to type 1 error, and a more faithful replication of this work would be useful for better understanding the partitioning paradox, if it in fact exists. Additionally, although we did not specifically tell participants to eat the 
M\&M's, our prompts to begin eating (by asking about likeability of taste of M\&M's) was perhaps too encouraging to start eating, and they experienced lapse in self-control.

Similarly, although our study was not intended to be a "taste test," it is feasible that our questions surrounding M\&M likeability prompted eating behaviour and was comparable to previous research on bogus taste tests. The bogus taste test involves providing participants with food items and requesting they rate the food on taste perceptions. However, the true purpose of the taste test is to measure consumption behaviour in a disguised and objective manner. A review conducted by Robinson et al. (2017) found that being male, having a higher hunger baseline, liking the taste of the food item, and having a greater tendency to overeat in response to palatable foods was reliable associated with increased consumption on the bogus taste test. However, the review found that dietary restraint and BMI was not was not reliably associated with food intake on a bogus taste test. Given that the present study closely resembled a bogus taste test by requesting participants indicate how much they liked M\&M's, the review by Robinson et. al (2017; which found that dietary restrained was not reliably associated with food intake on a bogus taste test) could explain why the present study did not find any effects of dietary restraint on consumption behaviour.

Finally, there was no significant difference on consumption for small and large packages for the control group. This is highly unusual given the overwhelming amount of research that found that people typically eat more in large packages and less in small packages. Again, it is possible that our paradigm to encourage eating may have impacted these findings. As an ad hoc test of this suspicion, we repeated the same $2 \times 2 \times 3$ between subjects ANOVA, removing all participants who ate fewer than two M\&M's. 
This arguably would roughly mirror what would happen if participants were not implicitly encouraged to taste at least one candy for their "consumer preference task." In this reanalysis, a main effect of package size was present. Participants in the "small" condition $(M=26.58, S E=2.01)$ ate significantly fewer M\&M's than participants in the "large" condition $(M=33.25, S E=2.13)$ upon removing individuals who ate fewer than 2 M\&M's.

Future research directions on dietary restraint, package size, and diet / body image primes should explore the impact of the size of the "small" package size, mindful and mindless filler tasks while exposed to the food, and the effects of encouraging participants to taste the snacks compared to having no prompts during the filler eating task. Understanding the theoretical foundations of cognitive restraint in these circumstances will guide future research on snack consumption behaviour. 


\section{Appendix A}

\section{The Revised Restraint Scale}

1. How often are you dieting?

0 - Never

1 - Rarely

2 - Sometimes

3 - Usually

4 - Always

2. What is the maximum amount of weight (in pounds) you have ever lost within 1 month?

$0-0-4 \mathrm{lbs}$

$1-5-9 \mathrm{lbs}$

$2-10-14 \mathrm{lbs}$

$3-15-19 \mathrm{lbs}$

$4-20+1 b s$

3. What is the maximum amount of weight gain (in pounds) within a week?

$0-0-1 \mathrm{lbs}$

$1-1.1-2 \mathrm{lbs}$

$2-2.1-3 \mathrm{lbs}$

$3-3.1-5 \mathrm{lbs}$

$4-5+1 b s$

4. In a typical week, how much does your weight fluctuate?

$0-0-1 \mathrm{lbs}$

$1-1.1-2 \mathrm{lbs}$

$2-2.1-3 \mathrm{lbs}$

$3-3.1-5 \mathrm{lbs}$

$4-5.1+\mathrm{lbs}$

5. Would a weight fluctuation of 5 pounds affect the way you live your life?

$0-$ Not at all

1 - Slightly

2 - Moderately

3 - Very Much

6. Do you eat sensibly in front of others and splurge alone?

0 - Never

1 - Rarely

2 - Often

3 - Always 
7. Do you give too much time and thought to food?

0 - Never

1 - Rarely

2 - Often

3 - Always

8. Do you have feelings of guilt after overeating?

0 - Never

1 - Rarely

2 - Often

3 - Always

9. How conscious are you of what you are eating?

0 - Not at all

1 - Slightly

2 - Moderately

3 - Very Much

10. How many pounds over your desired weight were you at your maximum weight?

$0-0-1 \mathrm{lbs}$

$1-1-5 \mathrm{lbs}$

$2-6-10 \mathrm{lbs}$

$3-11-20 \mathrm{lbs}$

$4-21+\mathrm{lbs}$ 


\section{Appendix B}

\section{Demographic Questionnaire}

1. Age:

2. Gender (select one): Male Female Other

3. Race/Ethnic Origin: (Please check all that apply)

$\square$ Aboriginal (e.g., Inuit, Métis, North American Indian)

$\square$ Arab/West Asian (e.g., from Egypt, Iran, Lebanon, Morocco)

$\square$ Black (e.g., Africa, Haiti, Jamaica, Somalia)

$\square$ East Asian (e.g., China, Japan, Korea)

$\square$ Latin American (e.g., Mexico, Brazil, Columbia)

$\square$ South Asian (e.g. India, Sri Lanka, Nepal)

$\square$ South East Asian (e.g., Thailand, Philippines, Indonesia)

$\square$ White (e.g., Caucasian, European)

$\square$ If none of the above, please specify: 


\section{Appendix C}

\section{Flowchart of Methodology}

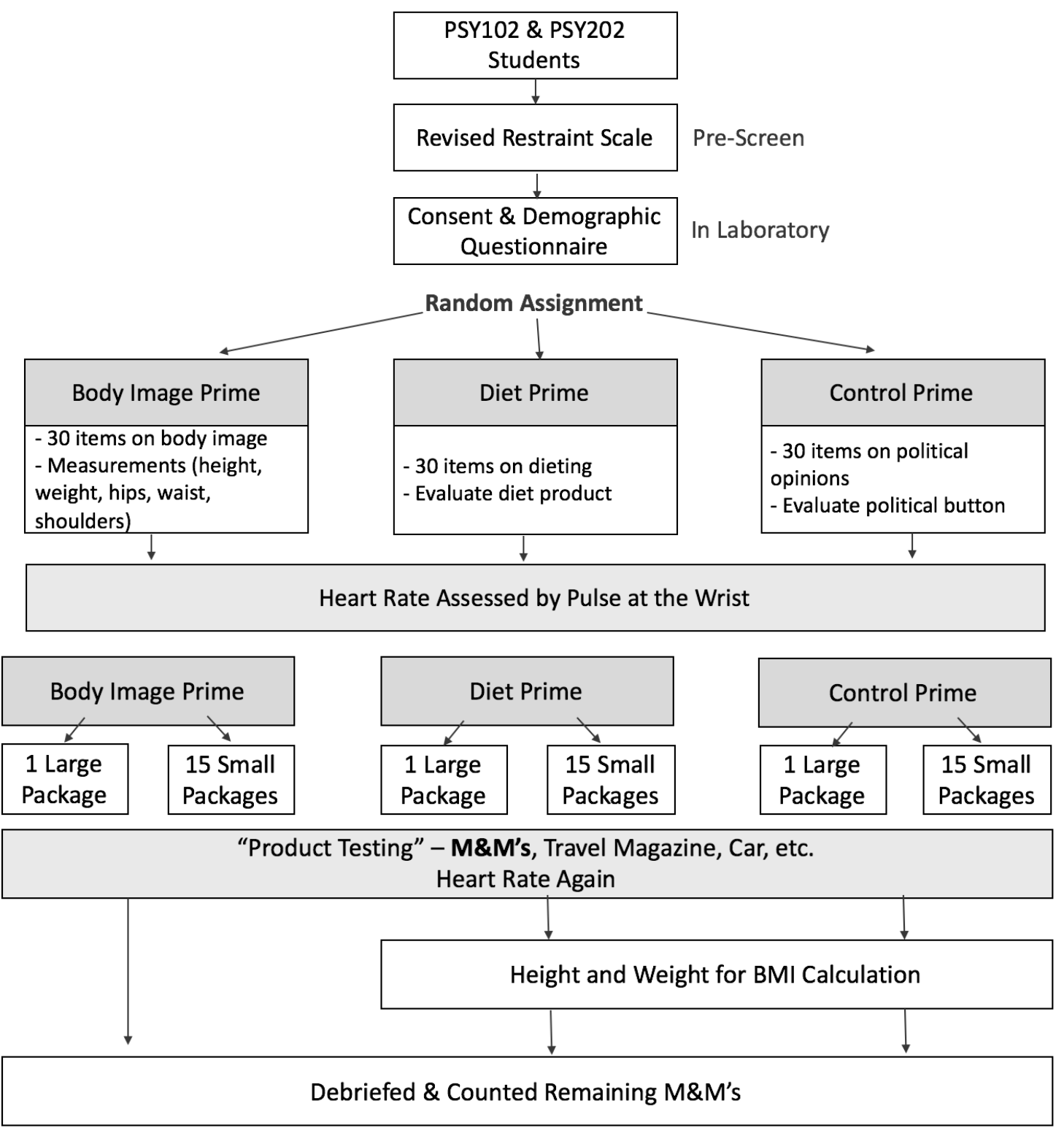




\section{Appendix D}

\section{Image of Package Sizes}

1. Fifteen small packages

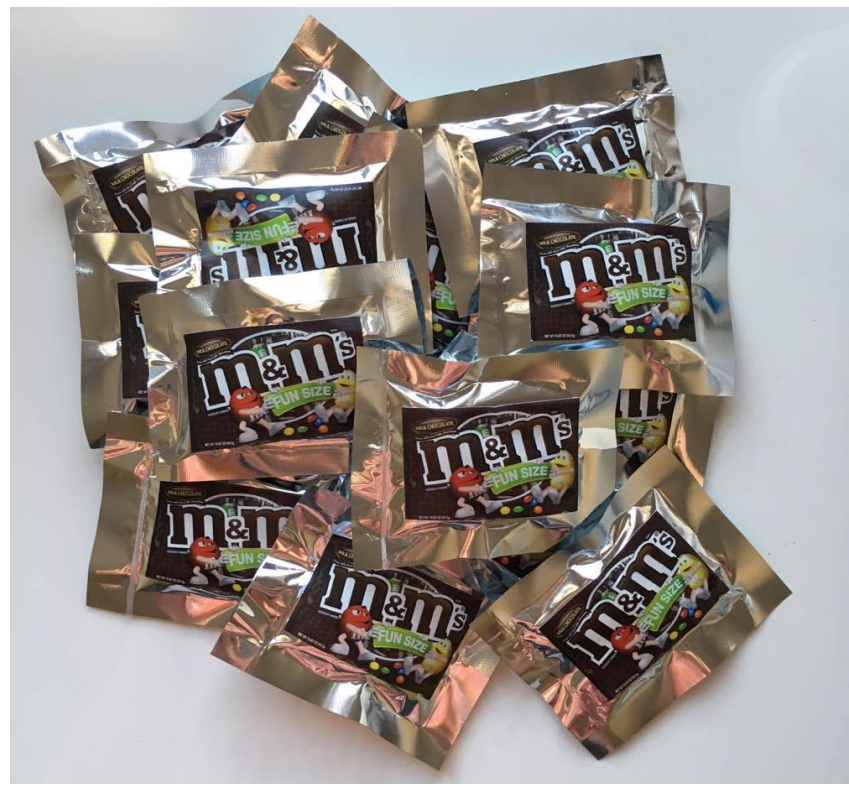

2. One large package

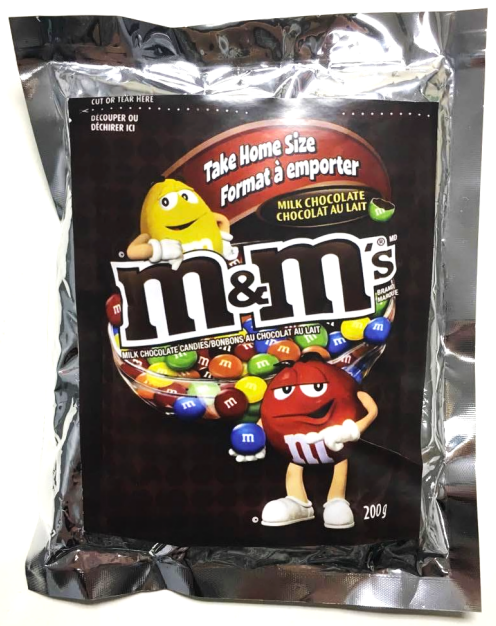




\section{Appendix E}

\section{Activating Body Consciousness Scale}

\section{A. Body Satisfaction Subscale}

For each item, please indicate the description that best characterizes your feelings or behaviours (Always, Usually, Often, Sometimes, Rarely, Never).

1. I think that my stomach is too big.

2. I think that my thighs are too large.

3. I think that my stomach is just the right size.*

4. I feel satisfied with the shape of my body.*

5. I like the shape of my buttocks.*

6. I think my hips are too big.

7. I think that my thighs are just the right size.*

8. I think my buttocks are too large

9. I think that my hips are just the right size.*

\section{B. Body Parts Satisfaction Subscale}

For each item, please indicate the description that best characterizes your feelings or behaviours:
a. Extremely satisfied
b. Quite Satisfied
c. Somewhat Satisfied
d. Somewhat Dissatisfied
e. Quite Dissatisfied
f. Extremely dissatisfied

How satisfied are you with the way your body looks?
1. Height
2. Weight
3. Shoulders
4. Breasts/Chest
5. Arms
6. Size of Abdomen/Stomach
7. Buttocks
8. Hips (upper thighs)
9. Legs and Ankles
10. General Muscle Tone
11. Overall Body Appearance 


\section{Body Shape Questionnaire}

We would like to know how you have been feeling about your appearance over the PAST FOUR WEEKS.
1. Never
2. Rarely
3. Sometimes
4. Often
5. Very Often
6. Always

1. Have you been afraid that you might become fat (or fatter)?

2. Have you ever felt so bad about your shape that you have cried?

3. Has being with [thin women/fit men] made you feel self-conscious about your shape?

4. Have you noticed the shape of other [women/men] and felt that your own shape compared unfavourably?

5. Has being naked, such as when taking a bath, made you feel fat?

6. Have you felt excessively large and rounded?

7. Have you ever felt ashamed of your body?

8. Have you worried about other people seeing rolls of flesh around your waist or stomach?

9. Has seeing your reflection (e.g., in a mirror or shop window) made you feel bad about your shape?

10. Have you avoided situations where people could see your body? (e.g., communal changing rooms, or swimming pools)? 


\section{Appendix F}

\section{Activating Diet Consciousness Scale}

\section{A. Drive for Thinness Scale Subscale}

For each item, please indicate the description that best characterizes your feelings or behaviours (Always, Usually, Often, Sometimes, Rarely, Never).

1. Eating sweets and carbohydrates makes me feel nervous.

2. I think about dieting.

3. I feel extremely guilty after overeating.

4. I am terrified of gaining weight.

5. I exaggerate or magnify the importance of weight.

6. I am preoccupied with the desire to be thinner.

7. If I gain a pound, I worry that I will keep gaining.

\section{B. Three-Factor Eating Questionnaire Subscale} Part 1 - True/False

1. I usually eat too much at social occasions, like parties and picnics.

2. I deliberately take small helpings as a means of controlling my weight.

3. I have a pretty good idea of the number of calories in common food.

4. Sometimes when I start eating, I just can't seem to stop.

5. While on a diet, if I eat food that is not allowed, I consciously eat less for a period of time to make up for it.

6. When I see a delicious treat, I often get so hungry that I have to eat right away.

7. I often stop eating when I am not really full as a conscious means of limiting the amount that I eat.

8. I am always hungry so it is hard for me to stop eating before I finish the food on my plate.

9. I consciously hold back at meals in order not to gain weight.

10. I count calories as a conscious means of controlling my weight.

11. I do not eat some foods because they make me fat.

Part 2 - For each item, please indicate the description that best characterizes your feelings or behaviours (Rarely, Sometimes, Usually, Always)

12. Do your feelings of guilt about overeating help you to control your food intake?

13. How conscious are you of what you are eating?

14. How likely are you to shop for low calorie foods?

15. How frequently do you skip dessert because you are no longer hungry?

16. How likely are you to consciously eat less than you want? 


\section{Current Dieting Questionnaire Subscale (CDQ)}

1. True/False - I am trying to lose weight by eating less

2. True/False - I choose foods that are low in fat because I am trying to lose weight.

3. Yes/No - Are you now watching what you eat in order to lose weight?

\section{Bratman Orthorexia Scale}

Yes/No

1. Is the nutritional value of your meal more important than the pleasure of eating it?

2. Does your self-esteem get a boost from eating healthily?

3. Have you given up foods you used to enjoy in order to eat the 'right' foods

4. Do you feel guilty when you stray from your diet? 


\section{Appendix G}

\section{Activating Diet Consciousness Behavioural Component}

\section{Evaluate a Diet Product}

1. Why do you think these products are healthy?

2. If I use these products (circle one)
A. I will lose weight.
True False
B. It will be easier for me to stay on a diet.
True False
C. It will help me eat less.
True False
D. I will be taking a safe weight-loss product.
True False

3. What do you like about the products packaging?

4. Do you find the front of package nutritional labeling to be helpful?

Picture of Blue Menu Products:

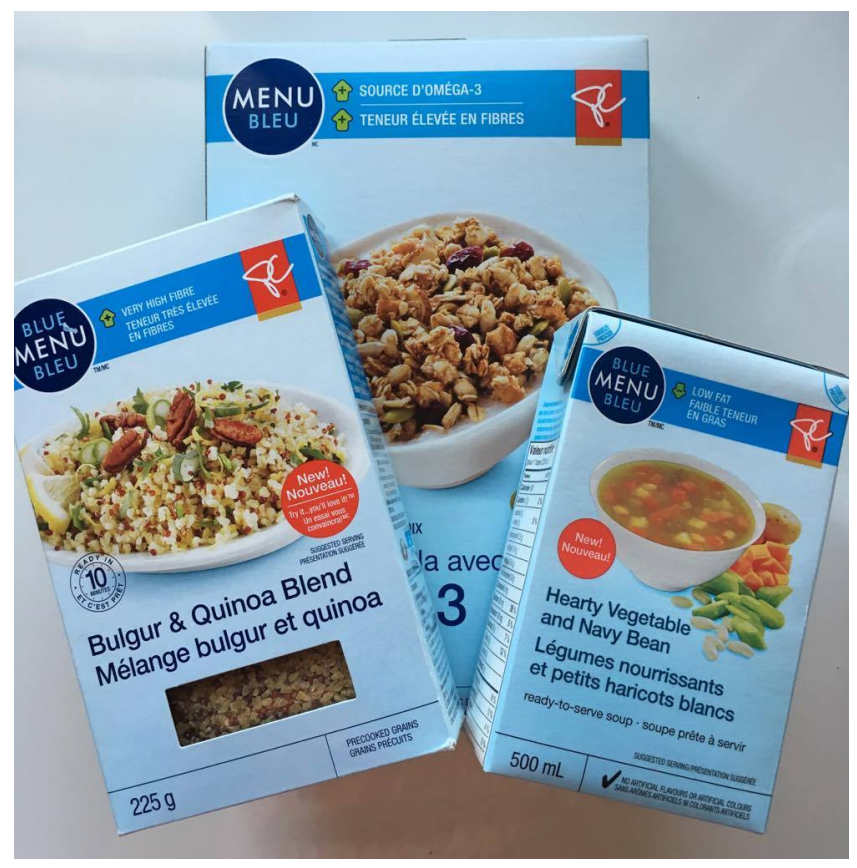




\section{Appendix $\mathbf{H}$}

\section{Control Questionnaire: Political Affiliation Scale (e.g., Body Neutral)}

1. Should the federal government put a cap on university tuition rates?

a. Yes / No / Other stances

2. Should postsecondary education be a provincial or federal responsibility?

a. Provincial / Federal / Other stances

3. Should the government increase environmental regulations on businesses to reduce carbon emissions?

a. Yes / No / Other stances

4. Should the federal government subsidize the production and consumption of renewable energy sources?

a. Yes / No / Other stances

5. Should the government allow TransCanada to expropriate private property for the construction of the Keystone pipeline?

a. Yes / No / Other stances

6. Do you support the Northern Gateway pipeline project?

a. Yes / No / Other stance / Not familiar with this project

7. Should Canada allow the logging of old growth forests?

a. Yes / No / Other stances

8. Should Canada raise or lower the tax rate for corporations?

a. Raise / Lower / Other stances

9. Should the pensions of retired workers be taxed?

a. Yes / No / Other stances

10. Should Canada pursue free trade deals with other countries?

a. Yes / No / Other stances

11. Should the federal government subsidize universal child care?

a. Yes / No / Other stances

12. Should old age pensions be increased?

a. Yes / No / Other stances

13. Do you support income splitting for families?

a. Yes / No / Other stances

14. Should the employee contribution rate for the Canadian Pensions Plan (CPP) be raised above its current $4.49 \%$ rate?

a. Yes / No / Other stances

15. Should employment insurance be given to those who work seasonal jobs including tourism, fishery and farming?

a. Yes / No / Other stances

16. Should the government classify Bitcoin as a legal currency?

a. Yes /No / Other stance / Not familiar with Bitcoin

17. Should Quebec be granted sovereignty from the rest of Canada?

a. Yes / No / Other stances

18. Should government workers be allowed to strike?

a. Yes / No / Other stances 
19. Do you support a national daycare policy?

a. Yes / No / Other stances

20. Should the federal government invest in urban, commuter rail infrastructure?

a. Yes / No / Other stances

21. Should the federal government require children be vaccinated from preventable diseased?

a. Yes / No / Other stances

22. Should prescription drugs be covered under Canada's universal healthcare plan?

a. Yes / No / Other stances

23. Should preventative dental care be covered under Canada's universal healthcare plan?

a. Yes / No / Other stances

24. Should healthcare be a provincial or federal responsibility?

a. Provincial / Federal / Other stances

25. Should the federal government increase spending on healthcare?

a. Yes / No / Other stances

26. Should there be more or less privatization of hospital and healthcare services?

a. Yes / No / Other stances

27. Should the government permit the use of drones from commercial purposes?

a. Yes / No / Other stances

28. Should term limits be set for the role of Prime Minister?

a. Yes / No / Other stances

29. Should corporations, unions, and non-profit organizations be allowed to donate to political parties?

a. Yes / No / Other stances

30. Do you identify as more Liberal or Conservative?

a. Mostly Liberal / Mostly Conservative / Other 


\section{Appendix I}

\section{Control (Body Neutral) Behavioural Component}

\section{Evaluate a Political Logo}

1. I enjoy the colours of this logo.
True
False
Neutral

2. If I had to change the colours of this logo, I would select the following two colours:

Colour 1:

Colour 2:

3. Does this logo stand out and catch your eye?

$1-$ Not at all

2 - A little bit

3 - Very much so

$4-\mathrm{A}$ lot

4. Is this logo memorable?

$1-$ Not at all

3 - Very much so

2 - A little bit

$4-\mathrm{A}$ lot

5. Is this logo professional?

$1-$ Not at all

3 - Very much so

2 - A little bit

$4-\mathrm{A}$ lot

6. If you could improve this logo, what would you change?

Picture of Political Logo:

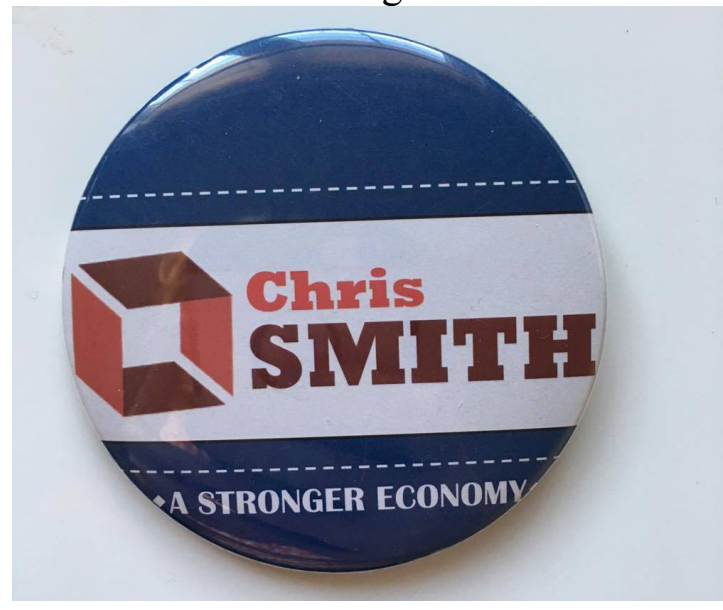




\section{Appendix J}

\section{Informed Consent Form}

\section{"Physical and Psychological Factors in Consumer Preferences"}

You are being invited to participate in a research study. Before you give your consent to be a volunteer, it is important that you read the following information and ask as many questions as necessary to be sure you understand what you will be asked to do.

\section{Investigators:}

Katey Park, B.A., Department of Psychology, Ryerson University, Toronto. Michelle M. Dionne, Ph.D., Department of Psychology, Ryerson University, Toronto.

Purpose of the Study: This is a study of how psychological attitudes and some basic physical variables can interact in predicting certain consumer behaviours and preferences. We are hoping to include 240 university students in this study. Some of the results of this study may be used by graduate student Katey Park in partial completion of the requirements for her Master's degree at Ryerson.

\section{What you will be asked to do:}

Participation in this study will require one 60 minute visit to our lab. During your visit, you will be asked to complete questions (presented on a computer, in private) about selfattitudes and self-descriptors. We would also like to take some simple physiological measurements like resting heart rate and body size (e.g., height and weight). Finally, you will also be asked to assess some common commercial products and logos for consumer research, including $\mathrm{m} \& \mathrm{~m}$ candies, a sweater, a brand of automobile, and a travel destination.

Potential Benefits of the Study: There is no direct benefit to participants in this study although the information gained from the overall study may improve our understanding of the relationship between attitudes about the self and consumer research. Once the study is completed (anticipated to be spring 2017) please contact us and we would be happy to share those results.

\section{Risks and Discomforts:}

There are no known risks to completing the tasks, questionnaires or body size measurements in this study. However, because of the personal nature of the information requested, some individuals may feel uncomfortable upon reflecting on certain attitudes and behaviors. Any discomfort is expected to be temporary and not greater than you might experience in a typical day. If you have dietary restrictions that would preclude you from eating m\&m's you should not participate in that part of the study. If any aspect of this study makes you uncomfortable, you may temporarily or permanently discontinue your participation without penalty or loss of benefit to which you are entitled. 
Confidentiality: All information collected during this study will be confidential because your name, contact information and student number will not appear anywhere on the questionnaires, measurements, or data. Rather, your information will be identified by a number only. Any identifying information from this study will be held in a locked lab room to which only the investigators and their research assistants will have access.

\section{Incentives to Participate:}

Signing up through SONA (e.g., the Intro Psychology Research Participant Pool), means that you will receive 1\% towards your final mark in PSY102/202. This will be credited immediately following your lab visit.

Voluntary Nature of Participation: Participation in this study is voluntary. Your choice of whether or not to participate will not influence your grades, academic status, or future relations with Ryerson University or the Department of Psychology. If you decide to participate, you are free to withdraw your consent and to stop your participation at any time without penalty or loss of benefits to which you are allowed. Further, at any time during the current academic term you may withdraw your consent and request that your data be removed from the data set. Should you choose to withdraw from the study, you will still be compensated for your participation. You are also free to choose to "walkthrough" the study without penalty or loss of benefits. This will allow you to experience participation in the study but your data will not be included in the final data set.

Questions: If you have any questions about the research now, please ask. If you have questions later about the research you may contact either of the following investigators:

Katey Park (416) 979-5000 ext.4694 katey.park@ryerson.ca

Dr. Michelle Dionne (416) 979-5000 ext.4694_mdionne@ryerson.ca

If you having any questions regarding your rights as a human subject and participant in this study, you may contact the Ryerson University Research Ethics Board for information:

Ryerson Ethics Board c/o Office of the Vice President, Research and Innovation

Ryerson University 350 Victoria Street Toronto, ON M5B 2K3 416-979-5042

rebchair@,ryerson.ca

If completing any of these measurements raises concerns that you would like to discuss, please contact the: Centre for Student Development and Counselling (CSDC) Ryerson University Jorgenson Hall (JOR-07C) 416-979-5195 csdc@ryerson.ca

If you any have questions about receiving your Psychology 102/202 credit for participation please contact: SONA/ PsychPool thepool@psych.ryerson.ca

Agreement: Your checkmark below indicates that you have read the information in this agreement and have had a chance to ask any questions you have about the study. By checking that box, you also indicate that you agree to be in the study and have been told that you can change your mind and withdraw your consent to participate at any time, and 
have your data removed from the dataset. You have been offered a copy of this agreement.

You have been told that by initiating this consent agreement you are not giving up any of your legal rights.

Note that this form will be presented, and agreement / consent will be indicated via a check box on QUALTRICS rather than a hard copy signature. 


\section{Appendix K}

\section{Filler Questionnaires during Eating Task}

You will have 15 minutes to complete all five evaluations. Even if you complete the task early, we will need to re-test your heart rate again in 15 minutes, so please remain in the room until I notify you that the time is up.

\section{Product \#1: M\&M's Chocolate [Note: either multiple small or one large pack was provided to participants]}

1. Have you ever purchased this product in the past?

a. Yes / No

2. If yes, how many times in the past month have you purchased this product?

a. $1 / 2 / 3 / 4 / 5+$

3. Have you seen this product advertised?

a. Yes / No

4. If yes, where have you seen this product advertised? Select all that apply.

a. Television / Billboards / Social media / In stores / Magazines / Other:

5. Do you enjoy the taste of this product?

a. Yes / No / Unsure

6. How visually appealing is the product's packaging?

a. 1 - Not at all appealing, 2 - A little bit appealing, 3 - Quite appealing, 4 Extremely appealing

7. If you could improve this product, what would you change?

Product \#2: Sweater

1. How visually appealing is this sweater?

1 - Not at all appealing $\quad 3$-Quite appealing

2 - A little bit appealing $\quad 4$ - Extremely appealing

2. How comfortable would you rate this sweater to be?

1 - Not at all comfortable 3 -Quite comfortable

2 - A little bit comfortable 4 - Extremely comfortable

3. How likely would you be to purchase this sweater?

1 - Not at all likely $\quad 3$ - Quite likely

2-A little bit likely $\quad 4$-Extremely likely

4. If I use this product, I will be using a product made by a reputable company.

$\begin{array}{lll}\text { True } & \text { False } & \text { Neutral }\end{array}$

5. If you could improve this product, what would you change? 
Product \#3: Picture of Car

If I use this product:

1. I will be using a safe vehicle.

True False Neutral

2. I will be using a product made by a reputable manufacturer.

True False Neutral

3. I will be using a family-friendly vehicle.

True False Neutral

4. I will be using a luxury vehicle.

True False Neutral

5. I will be using a vehicle that is good on gas.

True $\quad$ False $\quad$ Neutral

Product \#4: Two Travel Magazines

Magazine 1: (Top Deck)

1. How appealing is it to travel to this location? (Africa)

1 - Not at all appealing 3 -Quite appealing

2 - A little bit appealing $\quad 4$ - Extremely appealing

2. What would be your largest barriers that would prevent you from traveling to this location? (Circle all that apply)

1 - Price

2 - Dislike long flights

3 - Worry about food

4 - Worry about climate/heat

5 - Worry about safety

6 - Other

7 - No desire to travel to this location

3. What is this African vacation most appealing for? (Circle all that apply)

1- Honeymoon

2 - Families

3 - Romantic Getaways

4 -Destination weddings

5 - Group of friends

6 - Solo trips

7 - Other: 
4. On a scale of 1 to 10 , how appealing are the photos in this magazine?

$\begin{array}{llllllllll}1 & 2 & 3 & 4 & 5 & 6 & 7 & 8 & 9 & 10\end{array}$

5. Please browse through the magazine. What activities would you be most interested in partaking in, if you traveled to this location?

Magazine 2: (Cosmos)

1. How appealing is it to travel to this location? (United States and Canada)

1 - Not at all appealing $\quad 3$-Quite appealing

2 - A little bit appealing $\quad 4$-Extremely appealing

2. What would be your largest barriers that would prevent you from traveling to this location? (Circle all that apply)

1 - Price

2 - Dislike long flights

3 - Worry about food

4 - Worry about climate/heat

5 - Worry about safety

6 - Other

7 - No desire to travel to this location

3. What is this American and Canadian vacation most appealing for? (Circle all that apply)

1 - Honeymoon

2 - Families

3 - Romantic Getaways

4 -Destination weddings

5 - Group of friends

6 - Solo trips

7 - Other:

4. On a scale of 1 to 10 , how appealing are the photos in this magazine?

$\begin{array}{llllllllll}1 & 2 & 3 & 4 & 5 & 6 & 7 & 8 & 9 & 10\end{array}$

5. Please browse through the magazine. What activities would you be most interested in partaking in, if you traveled to this location?

6. Which magazine do you prefer most?

Cosmos Topdeck 


\section{Appendix L}

\section{Debrief Form}

\section{Debriefing Form: Physical and Psychological Factors in Consumer Preferences}

You have participated in a research study conducted by Dr. Michelle Dionne and Katey Park, from the Dept. of Psychology at Ryerson.

Background Information: Research has shown that people who are conscious and continually aware of their eating behaviour, may increase eating behaviour of food packaged in smaller portions. Thus, food packaging that is designed to limit eating behaviour (such as "100-calorie" packs) may have the reverse of its intended effects, and actually cause chronic dieters to eat more. Some research has shown that activating people to "self-regulate" (for example, by enhancing body consciousness) causes an increase in eating food from smaller packaging, and a decrease in eating from larger packaging. However, no research to date has studied whether it is activating body consciousness, or activating diet consciousness, that causes this trend to emerge.

Purpose of the Study: In this study, we wanted to understand why and under what conditions people will eat more food from smaller packages. This research interest has real-world relevance because chronic dieters are more likely to buy portion-controlled packaging (such as "100 calorie" packs), and also may be more likely to eat more food in this format. We are also interested in discovering whether body image activation, or diet conscious activation, causes this trend to emerge.

\section{Design of the Study:}

In this study, we randomly assigned participants to complete questionnaires on (1) body image, (2) dieting behaviour, or (3) a neutral condition (political affiliation). Participants in each group also completed a behavioural component (1): body measurements; (2) evaluating a diet product or (3) evaluating a political logo and slogan. Next, all participants were requested to evaluate a some consumer products (m\&ms, a sweater, a car, and a travel destination) but we were actually only interested in the consumption of the tempting snack (m\&m's). Although you were led to believe that you were simply assessing a variety of products/logos, in reality, researchers were interested in measuring how much food was consumed in each of the 3 groups named above. We also will consider scores on a dietary restraint questionnaire that you would have completed previously. We regret this deception, but felt that it was necessary to mask the true nature of the study to maintain the validity of the results.

\section{Expected Results:}

We expect to find that people who are chronic dieters will consume more food from snacks in smaller packaging and that the effect will be pronounced in those who are activated for body image concerns and/or diet concerns, compared to a comparison group. 


\section{Questions and Concerns:}

If you feel any distress that you would like to discuss, please contact the: Centre for Student Development and Counselling (CSDC) located in Jorgenson Hall (JOR-07C), 416-979-5195, csdc@ryerson.ca

If you have questions about this study or would like to remove your data from the study, please contact one of the below investigators. You may also contact us after June 2017 if you would like to receive a copy of the results from this study.

Dr. Michelle Dionne

(416) 979-5000 ext.7103 mdionne@ryerson.ca

Katey Park

(416) 979-5000 ext.4694ｋatey.park@,ryerson.ca

If you having any questions regarding your rights as a human subject and participant in this study, you may contact the Ryerson University Research Ethics Board for information:

Ryerson Ethics Board c/o Office of the Vice President, Research and Innovation Ryerson University 350 Victoria Street Toronto, ON M5B 2K3 416-979-5042

If you have question about receiving your Psychology 102 credit for participation please contact: thepool@psych.ryerson.ca

\section{References for further reading:}

Coelho Do Vale, Rita, Rik Pieters, and Marcel Zeelenberg (2008), "Flying under the Radar: Perverse Package Size Effects on Consumption Self-Regulation,” Journal of Consumer Research, 35 (October), 380-90.

Scott, M., Nowlis, S., Mandel, N., \& Morales, A. (2008). The effects of reduced food size and package size on the consumption behavior of restrained and unrestrained eaters. Journal of Consumer Research, 35(3), 391-405. Doi:10.1086/591103 


\section{References}

Almiron-Roig, E., Solis-Trapala, I., Dodd, J., \& Jebb, S. A. (2013). Estimating food portions. influence of unit number, meal type and energy density. Appetite, 71, 95-103. doi:10.1016/j.appet.2013.07.012

Andrés, A., \& Saldaña, C. (2014). Body dissatisfaction and dietary restraint influence binge eating behavior. Nutrition Research, 34(11), 944-950. doi:10.1016/j.nutres.2014.09.003

Anschutz, D. J., Van Strien, T., \& Engels, Rutger C. M. E. (2008). Exposure to slim images in mass media: Television commercials as reminders of restriction in restrained eaters. Health Psychology, 27(4), 401-408. doi:10.1037/0278-6133.27.4.401

Argo, J. J., \& White, K. (2012). When do consumers eat more? The role of appearance selfesteem and food packaging cues. Journal of Marketing, 76(2), 67

Baucom, D. H., \& Aiken, P. A. (1981). Effect of depressed mood on eating among obese and nonobese dieting and nondieting persons. Journal of Personality and Social Psychology, 41(3), 577-585. doi:10.1037//0022-3514.41.3.577

Baumeister, R. F., \& Heatherton, T. F. (1996). Self-regulation failure: An overview. Psychological Inquiry, 7(1), 1-15. doi:10.1207/s15327965pli0701_1

Becker, A. E. (2004). Television, disordered eating, and young women in fiji: Negotiating body image and identity during rapid social change. Culture, Medicine and Psychiatry, 28(4), 533-559. doi:10.1007/s11013-004-1067-5

Benton, D. (2015). Portion size: What we know and what we need to know. Critical Reviews in Food Science and Nutrition, 55(7), 988-1004. doi:10.1080/10408398.2012.679980 
Berg, C., Lappas, G., Wolk, A., Strandhagen, E., Torén, K., Rosengren, A.. . Lissner, L. (2009). Eating patterns and portion size associated with obesity in a swedish population. Appetite, 52(1), 21-26. doi:10.1016/j.appet.2008.07.008

Berscheid, E., Hatfield [Walster], E., \& Bohrnstedt, G. (1972). Body image - A Psychology Today Questionnaire. Psychology Today, 6, 57-67.

Berscheid E, Walster E, \& Bohmstedt G. (1973). Body image. The happy American body: A survey report. Psychology Today. 119-131.

Birch, L. L., Savage, J. S., \& Fisher, J. O. (2015). Right sizing prevention: food portion size effects on children's eating and weight. Appetite, 88, 11-16. doi:10.1016/j.appet.2014.11.021

Bratman, S. \& Knight, D. (2000). Health Food Junkies: Orthorexia Nervosa-Overcoming the Obsession with Healthful Eating. New York: Broadway Books.

Buckland, N. J., Finlayson, G., Edge, R., \& Hetherington, M. M. (2014). Resistance reminders: Dieters reduce energy intake after exposure to diet-congruent food images compared to control non-food images. Appetite, 73, 189-196. doi:10.1016/j.appet.2013.10.022

Canetti, L., Bachar, E., \& Berry, E. M. (2002). Food and emotion. Behavioural Processes, 60(2), 157-164. doi:10.1016/S0376-6357(02)00082-7

Chandon, P., \& Wansink, B. (2012). Does food marketing need to make us fat? A review and solutions. Nutrition Reviews, 70(10), 571-593. doi:10.1111/j.1753-4887.2012.00518.x

Cochran, W., \& Tesser, A. (1996). The "what-the-hell effect": Some effects of goal proximity and goal framing on performance. In L. L. Martin, \& A. Tesser (Eds.), Striving and feeling: Interactions among goals, affect, and self-regulation (pp. 99 - 120). Mahwah, NJ: Erlbaum. 
Coelho do Vale, R., Pieters, R., \& Zeelenberg, M. (2008). Flying under the radar: Perverse package size effects on consumption Self- Regulation. Journal of Consumer Research, 35(3), 380-390. doi:10.1086/589564

Cooper, P.J., Taylor, M.J., Cooper, Z., \& Fairburn, C.G. (1987). The development and validation of the Body Shape Questionnaire. International Journal of Eating Disorders, 6, 485-494. doi: 0.1002/1098-108X(198707)6:4<485::AID-EAT2260060405 >3.0.CO;2$\mathrm{O}$

Diliberti, N., Bordi, P. L., Conklin, M. T., Roe, L. S., \& Rolls, B. J. (2004). Increased portion size leads to increased energy intake in a restaurant meal. Obesity, 12(3), 562-568. doi:10.1038/oby.2004.64

Dykes, J., Brunner, E. J., Martikainen, P. T., \& Wardle, J. (2004;2003;). Socioeconomic gradient in body size and obesity among women: The role of dietary restraint, disinhibition and hunger in the Whitehall II study. International Journal of Obesity, 28(2), 262-268. doi:10.1038/sj.ijo.0802523

Fay, S. H., Ferriday, D., Hinton, E. C., Shakeshaft, N. G., Rogers, P. J., \& Brunstrom, J. M. (2011). What determines real-world meal size? evidence for pre-meal planning. Appetite, 56(2), 284-289. doi:10.1016/j.appet.2011.01.006

Ferguson, C. J. (2013). In the eye of the beholder: Thin-ideal media affects some, but not most, viewers in a meta-analytic review of body dissatisfaction in women and men. Psychology of Popular Media Culture, 2(1), 20-37. doi:10.1037/a0030766

Fishbach, A., \& Shah, J. Y. (2006). Self-control in action: Implicit dispositions toward goals and away from temptations. Journal of Personality and Social Psychology, 90(5), 820-832. doi:10.1037/0022-3514.90.5.820 
Fisher, J. O., \& Kral, T. V. E. (2008). Super-size me: Portion size effects on young children's eating. Physiology \& Behavior, 94(1), 39-47. doi:10.1016/j.physbeh.2007.11.015

Flood, J. E., Roe, L. S., \& Rolls, B. J. (2006). The effect of increased beverage portion size on energy intake at a meal. Journal of the American Dietetic Association, 106(12), 19841990. doi:10.1016/j.jada.2006.09.005

French, S. A., Mitchell, N. R., Wolfson, J., Harnack, L. J., Jeffery, R. W., Gerlach, A. F., Pentel, P. R. (2014). Portion size effects on weight gain in a free living setting. Obesity, 22(6), 1400-1405. doi:10.1002/oby.20720

Friedman, M. (2009). Sweet goods gain as at-home treats: Consumers desire indulgence, but they want smaller packages, easily plated portions and value, too. Refrigerated \& Frozen Foods Retailer, 7(8), 28.

Garner, D.M., Olmstead, M.P., \& Polivy, J. (1983). Development and validation of a multidimensional eating disorder inventory for anorexia nervosa and bulimia. International Journal of Eating Disorders, 2(2), 15-34.

Goldfield, G. S., Moore, C., Henderson, K., Buchholz, A., Obeid, N., \& Flament, M. F. (2010). Body dissatisfaction, dietary restraint, depression, and weight status in adolescents. The Journal of School Health, 80(4), 186-192. doi:10.1111/j.1746-1561.2009.00485.x

Government of Canada (2011). Estimated energy requirements. Retrieved from: https://www.canada.ca/en/health-canada/services/food-nutrition/canada-foodguide/food-guide-basics/estimated-energy-requirements.html

Haire, C., \& Raynor, H. A. (2014). Weight status moderates the relationship between package size and food intake. Journal of the Academy of Nutrition and Dietetics, 114(8), 1251. doi:10.1016/j.jand.2013.12.022 
Hausenblas, H. A., Campbell, A., Menzel, J. E., Doughty, J., Levine, M., \& Thompson, J. K. (2013). Media effects of experimental presentation of the ideal physique on eating disorder symptoms: A meta-analysis of laboratory studies. Clinical Psychology Review, 33(1), 168-181. doi:10.1016/j.cpr.2012.10.011

Heatherton, T. F., \& Polivy, J. (1992). Chronic dieting and eating disorders: A spiral model. In J. H. Crowther, D. L. Tennenbaum, S. E. Hobfoll, \& M. A. P. Stephens (Eds.), The etiology of bulimia nervosa: The individual and familial context (pp. 133 -155). Washington, DC: Hemisphere.

Heatherton, T. F., Polivy, J., Herman, C. P., \& Baumeister, R. F. (1993). Self-awareness, task failure, and disinhibition: How attentional focus affects eating. Journal of Personality, $61(1), 49$.

Herman, C. P., \& Mack, D. (1975). Restrained and unrestrained eating. Journal of Personality, 43(4), 647-660.

Herman, C. P., \& Polivy, J. (1975). Anxiety, restraint, and eating behavior. Journal of Abnormal Psychology, 84(6), 666-672.

Herman C. P., Polivy J. (1980). Restrained eating. In: Stunkard A, editor. Obesity (pp. 208-225). Philadelphia: Saunders.

Herman, C. P., \& Polivy, J. (1983). A boundary model for the regulation of eating. Psychiatric Annals, 13(12), 918-927. doi:10.3928/0048-5713-19831201-03

Herman, C. P., \& Polivy, J. (2004). The self-regulation of eating: Theoretical and practical problems. In R. F. Baumeister, \& K. D. Vohs (Eds.), Handbook of self-regulation: Research, theory, and applications (pp. 492 - 508). New York: Guilford Press. 
Herman, P. C., Polivy, J., Pliner, P., \& Vartanian, L. R. (2015). Mechanisms underlying the portion-size effect. Physiology \& Behavior, 144, 129-136.

doi:10.1016/j.physbeh.2015.03.025

Holden, S. S., \& Zlatevska, N. (2015). The partitioning paradox: The big bite around small packages. International Journal of Research in Marketing, 32(2), 230-233.

doi:10.1016/j.ijresmar.2015.03.002

Jeffery, R. W., Rydell, S., Dunn, C. L., Harnack, L. J., Levine, A. S., Pentel, P. R., Walsh, E. M. (2007). Effects of portion size on chronic energy intake. The International Journal of Behavioral Nutrition and Physical Activity, 4(1), 27-27. doi:10.1186/1479-5868-4-27

Kemps, E., Herman, C. P., Hollitt, S., Polivy, J., Prichard, I., \& Tiggemann, M. (2016). The role of expectations in the effect of food cue exposure on intake. Appetite, 103, 259-264. doi:10.1016/j.appet.2016.04.026

Kleef, v., E, Vet, d., E, \& Bruggers, I. (2015). Encouraging vegetable intake as a snack among children: The influence of portion and unit size. Public Health Nutrition, 18(15), 27362741. doi:10.1017/S1368980015001329

Kral, T. V. E., Kabay, A. C., Roe, L. S., \& Rolls, B. J. (2010). Effects of doubling the portion size of fruit and vegetable side dishes on children's intake at a meal. Obesity, 18(3), 521527. doi:10.1038/oby.2009.243

Kuijer, R. G., Boyce, J. A., \& Marshall, E. M. (2015). Associating a prototypical forbidden food item with guilt or celebration: Relationships with indicators of (un)healthy eating and the moderating role of stress and depressive symptoms. Psychology \& Health, 30(2), 203217. doi:10.1080/08870446.2014.960414 
Laessle, R. G., Tuschl, R. J., Kotthaus, B. C., \& Pirke, K. M. (1989). Behavioral and biological correlates of dietary restraint in normal life. Appetite, 12(2), 83-94. doi:10.1016/01956663(89)90098-6

Lee, J. M., Greening, L., \& Stoppelbein, L. (2007). The moderating effect of avoidant coping on restrained eaters' risk for disinhibited eating: Implications for dietary relapse prevention. Behaviour Research and Therapy, 45(10), 2334-2348. doi:10.1016/j.brat.2007.03.010

Levitsky, D. A., \& Youn, T. (2004). The more food young adults are served, the more they overeat. The Journal of Nutrition, 134(10), 2546.

Lowe, M. R. (1993). The effects of dieting on eating behavior: A three-factor model. Psychological Bulletin, 114(1), 100-121. doi:10.1037/0033-2909.114.1.100

Lowe, M. R., \& Thomas, J. G. (2009). Measures of restrained eating: Conceptual evolution and psychometric update. In M. R. Lowe (Ed.), Handbook of Assessment Methods of Eating Behaviors and Weight-Related Problems: Measures, Theory and Research. London: Sage Publications.

Madanat, H., Hawks, S., \& Christley, H. (2008). Behavioral and biological associations of dietary restraint: A review of the literature. Ecology of Food and Nutrition, 47(5), 415449. doi:10.1080/03670240701821444

Mathias, K. C., Rolls, B. J., Birch, L. L., Kral, T. V. E., Hanna, E. L., Davey, A., \& Fisher, J. O. (2012). Serving larger portions of fruits and vegetables together at dinner promotes intake of both foods among young children. Journal of the Academy of Nutrition and Dietetics, 112(2), 266-270. doi:10.1016/j.jada.2011.08.040 
McNelis, K. L. (2006). The effects of daily stress on eating behaviors: A comparison of restrained and unrestrained eaters (Unpublished Doctorial dissertation). Retrieved from American University, Washington D.C.

Miner-Rubino, K., Twenge, J. M., \& Fredrickson, B. L. (2002). Trait self-objectification in women: Affective and personality correlates. Journal of Research in Personality, 36(2), 147-172. doi:10.1006/jrpe.2001.2343

Nielsen, S. J., \& Popkin, B. M. (2003). Patterns and trends in food portion sizes, 1977-1998. Jama, 289(4), 450-453. doi:10.1001/jama.289.4.450

Nisbett, R. E. (1972). Hunger, obesity, and the ventromedial hypothalamus. Psychological Review, 79(6), 433-453. doi:10.1037/h0033519

Obesity: Can packaging help? (2005). Penton Media, Inc., Penton Business Media, Inc. and their subsidiaries.

Oliver, R. L., \& Bearden, W.O. (1985, December). Crossover effects in the theory of reasoned action: A moderating influence attempt. Journal of Consumer Research, 12, 324-340.

Ouwehand, C., \& Papies, E. K. (2010). Eat it or beat it. the differential effects of food temptations on overweight and normal-weight restrained eaters. Appetite, 55(1), 56-60. doi:10.1016/j.appet.2010.04.009

Papies, E. K., \& Hamstra, P. (2010). Goal priming and eating behavior: Enhancing selfregulation by environmental cues. Health Psychology, 29(4), 384-388. doi:10.1037/a0019877

Payne, C. R., Niculescu, M., \& Barney, C. E. (2014). Consumer consumption intentions of smaller packaged snack variants. International Journal of Consumer Studies, 38(3), 238242. doi:10.1111/ijcs. 12090 
Piernas, C., \& Popkin, B. M. (2011). Food portion patterns and trends among U.S. children and the relationship to total eating occasion size, 1977-2006. The Journal of Nutrition, 141(6), 1159. doi:10.3945/jn.111.138727

Polivy, J., Coleman, J., \& Herman, C. P. (2005). The effect of deprivation on food cravings and eating behavior in restrained and unrestrained eaters. International Journal of Eating Disorders, 38(4), 301-309. doi:10.1002/eat.20195

Polivy, J., Heatherton, T. F., \& Herman, C. P. (1988). Self-esteem, restraint, and eating behavior. Journal of Abnormal Psychology, 97(3), 354-356. doi:10.1037/0021$843 X .97 .3 .354$

Polivy, J., \& Herman, C. P. (1985). Dieting and binging: A causal analysis. American Psychologist, 40(2), 193-201. doi:10.1037/0003-066X.40.2.193

Polivy, J., \& Herman, C. P. (1999). The effects of resolving to diet on restrained and unrestrained eaters: The "false hope syndrome". International Journal of Eating Disorders, 26(4), 434-447. doi:10.1002/(SICI)1098-108X(199912)26:4<434::AIDEAT9>3.0.CO;2-0

Polivy, J., Herman, C. P., \& Deo, R. (2010). Getting a bigger slice of the pie: Effects on eating and emotion in restrained and unrestrained eaters. Appetite, 55(3), 426-430. doi:10.1016/j.appet.2010.07.015

Polivy, J., Herman, C. P., Olmsted, M. P., \& Jazwinski, C. (1984). Restraint and binge eating. In R. C. Hawkins, W. J. Fremouw, \& P. F. Clement (Eds.), The binge-purge syndrome: Diagnosis, treatment, and research (pp. 104 - 122). New York: Springer. 
Racine, S. E., Burt, S. A., Iacono, W. G., McGue, M., \& Klump, K. L. (2011). Dietary restraint moderates genetic risk for binge eating. Journal of Abnormal Psychology, 120(1), 119128. doi:10.1037/a0020895

Raynor, H. A., \& Wing, R. R. (2007). Package unit size and amount of food: Do both influence intake? Obesity, 15(9), 2311-2319. doi:10.1038/oby.2007.274

Rideout, C. A., McLean, J. A., \& Barr, S. I. (2004). Women with high scores for cognitive dietary restraint choose foods lower in fat and energy. Journal of the American Dietetic Association, 104(7), 1154-1157. doi:10.1016/j.jada.2004.04.024

Robinson, E., Aveyard, P., \& Jebb, S. A. (2015). Is plate clearing a risk factor for obesity? A cross-sectional study of self-reported data in US adults. Obesity, 23(2), 301-304. doi:10.1002/oby.20976

Robinson, E., Haynes, A., Hardman, C. A., Kemps, E., Higgs, S., \& Jones, A. (2017). The bogus taste test: Validity as a measure of laboratory food intake. Appetite, 116, 223-231. doi:10.1016/j.appet.2017.05.002

Rolls, B. J., Roe, L. S., Kral, T. V. E., Meengs, J. S., \& Wall, D. E. (2004). Increasing the portion size of a packaged snack increases energy intake in men and women. Appetite, 42(1), 63-69. doi:10.1016/S0195-6663(03)00117-X

Rolls, B. J., Roe, L. S., \& Meengs, J. S. (2006). Larger portion sizes lead to a sustained increase in energy intake over 2 days. Journal of the American Dietetic Association, 106(4), 543549. doi:10.1016/j.jada.2006.01.014

Rolls, B. J., Roe, L. S., \& Meengs, J. S. (2007). The effect of large portion sizes on energy intake is sustained for 11 days. Obesity, 15(6), 1535-1543. doi:10.1038/oby.2007.182 
Schmidt, J., \& Martin, A. (2015). Neurofeedback reduces overeating episodes in female restrained eaters: A randomized controlled pilot-study. Applied Psychophysiology and Biofeedback, 40(4), 283-295. doi:10.1007/s10484-015-9297-6

Scott, M., Nowlis, S., Mandel, N., \& Morales, A. (2008). The effects of reduced food size and package size on the consumption behavior of restrained and unrestrained eaters. Journal of Consumer Research, 35(3), 391-405. doi:10.1086/591103

Slade, P. D., Dewey, M. E., Newton, T, Brodie, D., \& Kiemle, G. (1990). Development and preliminary validation of the Body Satisfaction Scale (BSS). Psychology and Health, 4, $213-220$

Spence, M., Livingstone, M. B. E., Hollywood, L. E., Gibney, E. R., O'Brien, S. A., Pourshahidi, L. K., \& Dean, M. (2013). A qualitative study of psychological, social and behavioral barriers to appropriate food portion size control. The International Journal of Behavioral Nutrition and Physical Activity, 10, 92. doi:10.1186/1479-5868-10-92

Steenhuis, I. H., Leeuwis, F. H., \& Vermeer, W. M. (2010). Small, medium, large or supersize: Trends in food portion sizes in the Netherlands. Public Health Nutrition, 13(6), 852-857. doi:10.1017/S1368980009992011

Stice, E. (2001). A prospective test of the dual-pathway model of bulimic pathology: Mediating effects of dieting and negative affect. Journal of Abnormal Psychology, 110(1), 124-135. doi:10.1037//0021-843X.110.1.124

Stice, E., Davis, K., Miller, N. P., \& Marti, C. N. (2008). Fasting increases risk for onset of binge eating and bulimic pathology: A 5-year prospective study. Journal of Abnormal Psychology, 117(4), 941-946. doi:10.1037/a0013644 
Stroebele, N., Ogden, L. G., \& Hill, J. O. (2009). Do calorie-controlled portion sizes of snacks reduce energy intake? Appetite, 52, 793e796. http://dx.doi.org/10.1016/ j.appet.2009.02.015.

Stunkard, A. J., \& Messick, S. (1985). The three-factor eating questionnaire to measure dietary restraint, disinhibition and hunger. Journal of Psychosomatic Research, 29(1), 71-83. doi:10.1016/0022-3999(85)90010-8

Tanofsky-Kraff, M., Wilfley, D. E., \& Spurrell, E. (2000). Impact of interpersonal and egorelated stress on restrained eaters. The International Journal of Eating Disorders, 27(4), 411-418. doi:10.1002/(SICI)1098-108X(200005)27:4<411::AID-EAT5>3.0.CO;2-P

Thompson, S. (2006). Food marketers count on snacks: Consumers see the magic number 100, pay more for less. Advertising Age, 77(17), 4.

Trope, Y., \& Fishbach, A. (2000). Counteractive self-control in overcoming temptation. Journal of Personality and Social Psychology, 79(4), 493-506. doi:10.1037/0022-3514.79.4.493

Tuschl, R. J., Laessle, R. G., Platte, P., \& Pirke, K. (1990). Differences in food-choice frequencies between restrained and unrestrained eaters. Appetite, 14(1), 9-13. doi:10.1016/0195-6663(90)90050-I

van Strien, T., Frijters, J. E. R., Bergers, G. P. A., \& Defares, P. B. (1986). The Dutch eating behavior questionnaire (DEBQ) for assessment of restrained, emotional, and external eating behavior. International Journal of Eating Disorders, 5(2), 295-315. doi:10.1002/1098-108X(198602)5:2<295::AID-EAT2260050209>3.0.CO;2-T van Strien, T., Peter Herman, C., Engels, R. C. M. E., Larsen, J. K., \& van Leeuwe, J. F. J. (2007). Construct validation of the restraint scale in normal-weight and overweight females. Appetite, 49(1), 109-121. doi:10.1016/j.appet.2007.01.003 
Van Wymelbeke, V., Béridot-Thérond, M., de La Guéronnière, V., \& Fantino, M. (2004).

Influence of repeated consumption of beverages containing sucrose or intense sweeteners on food intake. European Journal of Clinical Nutrition, 58(1), 154-161. doi:10.1038/sj.ejen.1601762

Vartanian, L. R., Schwartz, M. B., \& Brownell, K. D. (2007). Effects of soft drink consumption on nutrition and health: A systematic review and meta-analysis. American Journal of Public Health, 97(4), 667-675. doi:10.2105/AJPH.2005.083782

Veling, H. P., \& Papies, E. K. (2013). Healthy dining: Subtle diet reminders at the point of purchase increase low-calorie food choices among both chronic and current dieters. Appetite, 61(1), 1-7. doi:10.1016/j.appet.2012.10.025

Versluis, I., \& Papies, E. K. (2016). Eating less from bigger packs: Preventing the pack size effect with diet primes. Appetite, 100, 70-79. doi:10.1016/j.appet.2016.02.011

Wansink, B. (2004). Environmental factors that increase the food intake and consumption volume of unknowing consumers. Annual Review of Nutrition, 24, 455e479. http://dx.doi.org/10.1146/annurev.nutr.24.012003.132140.

Wansink, B. (2007). Portion size me: Downsizing our consumption norms. J Am Diet Assoc, 107(7), 1103-1106. doi:10.1016/j.jada.2007.05.019

Wansink, B., \& Kim, J. (2005). Bad popcorn in big buckets: Portion size can influence intake as much as taste. Journal of Nutrition Education and Behavior, 37(5), 242-245. doi:10.1016/S1499-4046(06)60278-9

Wansink, B., Payne, C. R., \& Shimizu, M. (2011). The 100-calorie semi-solution: Subpackaging most reduces intake among the heaviest. Obesity, 19(5), 1098-1100. doi:10.1038/oby.2010.306 
Wardle, J., Steptoe, A., Oliver, G., \& Lipsey, Z. (2000). Stress, dietary restraint and food intake. Journal of Psychosomatic Research, 48(2), 195-202. doi:10.1016/S00223999(00)00076-3

Wertenbroch, K. (1998). Consumption self-control by rationing purchase quantities of virtue and vice: Abstract. Marketing Science (1986-1998), 17(4), 317.

What's the difference between a Food Guide serving, a serving size and a portion size? (2016). Retrieved from http://www.eatrightontario.ca/en/Articles/NutritionLabelling/What\%E2\%80\%99s-the-difference-between-a-Food-Guideserving.aspx\#.V6tkVa7Zotw

de Witt Huberts, J. C., Evers, C., \& de Ridder, D. T. D. (2013). Double trouble: Restrained eaters do not eat less and feel worse. Psychology \& Health, 28(6), 686. doi:10.1080/08870446.2012.751106

Wolff, G. E., Crosby, R. D., Roberts, J, A., \& Wittrock, D. A. (2000). Differences in daily stress, mood, coping, and eating behavior in binge eating and non-binge eating college women. Addictive Behaviors, 25, 205-216

Young, L. R., \& Nestle, M. (2002). The contribution of expanding portion sizes to the US obesity epidemic. American Journal of Public Health, 92(2), 246-249. doi:10.2105/AJPH.92.2.246

Young, L. R., \& Nestle, M. (2012). Reducing portion sizes to prevent obesity. American Journal of Preventive Medicine, 43(5), 565. doi:10.1016/j.amepre.2012.07.024 